Elsevier required licence: (C) <2019>. This manuscript version is made available under the CC-BY-NCND 4.0 license http://creativecommons.org/licenses/by-nc-nd/4.0/

The definitive publisher version is available online at

[https://www.sciencedirect.com/science/article/pii/S0960852418316638?via\%3Dihub] 


\title{
Microalgae biomass from swine wastewater and its conversion to bioenergy
}

\author{
D. L. Cheng, ${ }^{\mathrm{a}}$, H. H. Ngo ${ }^{\mathrm{a}, *}$, W. S. Guo ${ }^{\mathrm{a}, \mathrm{b}}$, S. W. Chang ${ }^{\mathrm{b}}$, D. D. Nguyen ${ }^{\mathrm{b}, \mathrm{c}}$, S. M. Kumar ${ }^{\mathrm{d}}$ \\ ${ }^{a}$ Centre for Technology in Water and Wastewater, School of Civil and Environmental Engineering, \\ University of Technology Sydney, Sydney, NWS 2007, Australia \\ ${ }^{b}$ Department of Environmental Energy \& Engineering, Kyonggi University, 442-760, Republic of Korea \\ 'Institution of Research and Development, Duy Tan University, Da Nang, Vietnam \\ ${ }^{d}$ Department of Civil Engineering, Indian Institute of Technology Madras, Chennai, Tamilnadu, India
}

$-600036$

* Corresponding author: H. H. Ngo; E-mail address:ngohuuhao121@gmail.com

\begin{abstract}
Ever-increasing swine wastewater (SW) has become a serious environmental concern. High levels of nutrients and toxic contaminants in SW significantly impact on the ecosystem and public health. On the other hand, swine wastewater is considered as valuable water and nutrient source for microalgae cultivation. The potential for converting the nutrients from SW into valuable biomass and then generating bioenergy from it has drawn increasing attention. For this reason, this review comprehensively discussed the biomass production, SW treatment efficiencies, and bioenergy generation potentials through cultivating microalgae in SW. Microalgae species grow well in SW with large amounts of biomass being produced, despite the impact of various parameters (e.g., nutrients and toxicants levels, cultivation conditions, and bacteria in SW). Pollutants in SW can effectively be removed by harvesting microalgae from SW, and the harvested microalgae biomass elicits high potential for conversion to valuable bioenergy.
\end{abstract}

Keywords: Swine wastewater, Microalgae, Nutrients, Toxicants, Biomass, Bioenergy

\section{Introduction}

Pork is the most widely consumed meat in the world according to the report named “Global Pork Meat Market 2017-2021” (Reportlinker, 2017). The rapid increase in pork 
demand has prompted the development of concentrated swine feeding operations, resulting in large quantities of SW production. SW contains not only high levels of suspended solids, organic matters, nutrients, but also toxicants, for example heavy metals, antibiotics and hormones (Cheng et al., 2018b). Concentrations of the above mentioned pollutants in SW are shown in Fig. 1 (Cheng et al., 2018a; Franchino et al., 2016; Markou et al., 2018; Pan et al., 2011). Therefore, direct discharge or insufficient treatment of SW can cause serious environmental pollution and risks to human health, particularly water eutrophication, soil pollution, antibiotic-resistant genes/ bacteria and estrogenic activity risks (Amini et al., 2016; Cheng et al., 2018b).

Anaerobic digestion is the most widely used technology for treating SW because this helps convert organic matter from SW into biogas, yet the removal of nutrients is curtailed (Cheng et al., 2018b). Global energy demands are growing with the increase of the population of world and the number of power-driven devices (Danquah et al., 2018). The escalating use of fossil fuels has serious implications for the finite supply of fossil fuels, but still contributing to rising greenhouse gas emissions (Abou-Shanab et al., 2013; Pittman et al., 2011).

For this reason, the development of renewable and sustainable alternatives is urgent, so that further aggravation of the energy crisis and global climate change can be avoided (Zhu et al., 2013b). Biofuels derived from biomass have been identified as alternatives to fossil fuels for alleviating world energy demands and reducing greenhouse emissions (Amin, 2009). However, the large-scale generation of biomass is to some extent restricted, because their continuous growth process requires large quantities of water and nutrients like nitrogen and phosphorus (Poorter \& Nagel, 2000). The addition of fresh water and commercial fertilizers to meet economic growth requirements can significantly increase the production costs, which is not cost-effective for biofuel production and energy recovery (Mata et al., 2010). Hence, 
the nutrient-rich SW is an excellent source for generating biofuel (Abou-Shanab et al., 2013; Salama et al., 2017).

Recently, the conversion of nutrients from SW into valuable plant biomass has attracted much attention. Not only can it treat wastewater in a simple, inexpensive and energy-efficient manner, it can also recycle the nutrients by producing bioenergy and biochemicals from postharvest biomass (Kumar et al., 2018; Liu et al., 2018a; Luo et al., 2018; Pittman et al., 2011). Compared to traditional biofuel crops, microalgae species were estimated as having high rates of biomass productivity and lipid contents, and they can grow well in concentrated wastewater and double in number within hours under optimal conditions (Mata et al., 2010). As reviewed by Pittman et al. (2011), microalgae can produce between 10- and 100-fold more oil per acre than terrestrial plants. Depending on different microalgae species, environmental conditions and cultivation methods, the harvested microalgae biomass can be used as feedstock for various bio-commodities production such as biodiesel, biogas, biohydrogen and other biofuels (Kumar et al., 2018; Markou et al., 2012; Rodolfi et al., 2009; Wang et al., 2017).

Therefore, this review aims to discuss on: (i) biomass production from SW and major impact factors; (ii) the ability of different microalgae species to remove pollutants; and (iii) bioenergy production potential by harvesting microalgae derived from SW. The recovery of nutrients and valuable materials from SW can reduce the cost of wastewater treatment and biomass production, while its bioenergy production can also mitigate our dependence on fossil fuels.

\section{Microalgae cultivation in swine wastewater}

The cultivation of microalgae with SW has been studied in-depth recently, with a focus on the production of biomass and its impact factors during the growth process (Prandini et al., 2016; Wang et al., 2015; Wang et al., 2017). Although SW is an ideal source for microalgae 
cultivation, high concentrations of pollutants in SW (see Fig. 1) might adversely affect the microalgae growth rate and biomass production. Generally, microalgae growth could be affected by initial nutrition levels, cultivation conditions (e.g., light intensity, temperature, $\mathrm{pH}$ and cultivation modes), heavy metals, antibiotics, hormones and bacteria in SW (Li et al., 2016; Miazek et al., 2015; Schnurr \& Allen, 2015; Zhang et al., 2012).

\subsection{Microalgae growth and biomass production}

The selection of robust strains that can consistently grow in SW is important for better production of bioenergy and SW purification (Ji et al., 2013a). The chosen microalgae should have high tolerance to the pollutants in SW, high growth rate, high recovery rate of nutrients, and robust growth properties with improved tolerance for varied environmental conditions (Salama et al., 2017). Several microalgae species (for instance, Chlorella sp., Scenedesmus sp., Neochloris sp., Chlorellaceae sp. and Coelastrella sp.) have been studied for SW treatment coupled with biomass production under various cultivation conditions (see Table $1)$.

Species in the genera Chlorella and Scenedesmus are the most employed microalgae cultivated in SW due to their high environmental tolerance, high biomass and lipid accumulation potential, Chlorella vulgaris and Scenedesmus obliquus in particular (Wang et al., 2016b). The maximum biomass concentration of Chlorella vulgaris $(4.25 \mathrm{~g} / \mathrm{L})$ is higher than Scenedesmus obliquus $(2.3 \mathrm{~g} / \mathrm{L})$ when they are cultivated in SW. As stated in Table 1, the microalgae biomass production and growth rate highly depend on microalgae species, cultivation conditions and SW compositions. The biomass concentrations of Chlorella vulgaris and Scenedesmus obliquus have a wide range in response to different culture conditions, with $0.2-4.25 \mathrm{~g} / \mathrm{L}$ and $0.24-2.3 \mathrm{~g} / \mathrm{L}$, respectively. Biomass productivity and specific growth rate are important parameters for assessing the microalgae growth scenario for all these studies microalgae species, which ranged from 29 to $890 \mathrm{mg} / \mathrm{L} / \mathrm{d}$ and $0.074-1.73$ 
$\mathrm{d}^{-1}$, respectively. SW has been regarded as suitable media for the growth of microalgae species for biomass production, despite the fact that comparing cultivation in different types of wastewater is not straight forward. This is due to the wide range of cultivation conditions applied (like cultivation mode, working volume, light intensity and temperature) that can affect biomass production (Kuo et al., 2015). Nevertheless, Ferreira et al. (2018) observed the maximum biomass production in SW by comparing the microalgae growth in different sources of wastewater (swine, poultry, cattle breeding, brewery, dairy, industrial and municipal wastewater) under the same operating conditions.

\subsection{Impact factors for microalgae growth and biomass production}

To enhance the economic feasibility of microalgae biofuel production, efficient growth and high biomass production of microalgae are required (Mata et al., 2010). The efficient growth of microalgae in SW depends significantly on cultivation conditions, nutrient and toxicant concentrations in SW (Amini et al., 2016). It can be seen from Table 1 that there is a wide range of growth and biomass production under different conditions, even the same species, which indicated that the culture medium and conditions are significant impact factors.

\subsubsection{Impact of nutrients in swine wastewater}

From Table 1, it should be noted that most microalgae species used in previous studies are cultivated in pretreated and/or diluted SW with either synthetic media or distilled water (Marjakangas et al., 2015). This is mainly attributed to: firstly, the high salinity as measured by ion conductivity in undiluted SW may induce osmotic stress and oxidative stress in the algal cells to inhibit their growth (Deng et al., 2018); secondly, suspended matter or impurities in the SW could compromise the water's clarity and interfere with light penetration (Wang et al., 2012); thirdly, the concentrated organic/inorganic compositions might inhibit the growth of microalgae (Park et al., 2010). Thus, the original SW wielded an 
adverse effect on the growth of microalgae species resulting in a very low biomass production (Franchino et al., 2016).

The microalgae biomass production and growth rate are affected by the SW dilution rate, because they strongly depend on the nutrients concentration of growth media. As summarized in Table 1, based on the initial nutrients concentration in SW, having a suitable dilution rate is important for biomass production and growth rate of microalgae. To be specific, microalgae growth could be inhibited if extremely high levels of nutrient are present in SW, so that more dilution is required. Conversely, greater dilution of SW can result in restricting the microalgae growth due to nutrient deficiencies. For example, Chlorella vulgaris grew better in the cultivation media with $5 \%$ of wastewater (initial nutrient concentrations: $\mathrm{TN}=3355, \mathrm{NH}_{4}-\mathrm{N}=2050$ and $\mathrm{TP}=318.5 \mathrm{mg} / \mathrm{L}$ ), and had higher biomass concentration $(1.47 \mathrm{~g} / \mathrm{L})$ and productivity $(229 \mathrm{mg} / \mathrm{L})$ when compared to cultivation in media with $10 \%$ of SW; no growth was observed in the media with $20 \%$ and 40\% SW (Franchino et al., 2016). Similar results have been reported by Ji et al. (2013b) and Ji et al. (2013a), who investigated the growth of Chlorella vulgaris YSW-04 and Scenedesmus obliquus YSW-14 in various diluted amounts of SW. They concluded that both the biomass concentration and specific growth rate of microalgae were the poorest in undiluted SW. The main reason for this could be that high concentrations of ammonium in undiluted SW inhibited the growth of microalgae (Park et al., 2010).

On the other hand, for the SW with relatively low concentrations of nitrogen and phosphorus, the microalgae growth and biomass production might decline with increasing dilution of SW. Research conducted by Marjakangas et al. (2015), Wang et al. (2016a) and Wang et al. (2017) all concluded that the highest values of biomass production and microalgae growth were obtained in undiluted SW with the initial concentrations of $\mathrm{TN}<300 \mathrm{mg} / \mathrm{L}$ and $\mathrm{TP}<30 \mathrm{mg} / \mathrm{L}$, respectively. Low phosphorus concentrations in the $\mathrm{SW}$ 
may be a limiting factor for microalgae biomass production (Ji et al., 2013a). Thus, increasing phosphate concentration could improve the biomass production by avoiding phosphate limitation (Wang et al., 2017). This outcome has been confirmed by Kuo et al. (2015), who observed that the maximum microalgae biomass production and specific growth rate were achieved in undiluted SW $(550 \mathrm{mg} / \mathrm{L}$ TN, $490 \mathrm{mg} / \mathrm{L} \mathrm{NH} 4-\mathrm{N}$ and $20 \mathrm{mg} / \mathrm{L}$ P) due to the deficiency of phosphorus. Hence, the appropriate dilution ratio of SW is essential to achieve the best cultivating conditions for microalgae biomass production.

\subsubsection{Impact of cultivation conditions}

In addition to nutrient levels in SW, the microalgae growth and biomass production depend significantly on cultivation conditions. Impact factors like $\mathrm{pH}$, temperature, growth modes, and the availability of light have been comprehensively reviewed elsewhere (Chew et al., 2018; Daliry et al., 2017; Singh \& Singh, 2015; Verma \& Srivastava, 2018). As reported in one study, each microalgae species has its own optimum range of $\mathrm{pH}$, temperature and light intensity at which it can function properly (Qiu et al., 2017). Hodaifa et al. (2009) and Daliry et al. (2017) discovered that $\mathrm{pH}$ in the 6-10 range was the optimum value for the growth of Chlorella vulgaris, Chlorella sorokiniana and Scenedesmus obliquus. Because of the high level of $\mathrm{NH}_{4}-\mathrm{N}$ in $\mathrm{SW}$, high $\mathrm{pH}$ could induce stripping of ammonia-nitrogen and result in high $\mathrm{NH}_{3}$ concentration, which can inhibit the growth of microalgae (Marjakangas et al., 2015). For the growing microalgae species in SW (as summarized in Table 1), the applied temperature and light intensity are in the $20-27^{\circ} \mathrm{C}$ and $45-300 \mu \mathrm{mol} / \mathrm{m}^{2} / \mathrm{s}$ ranges, respectively.

This is in consistent with Singh and Singh's (2015) findings, who concluded that the optimum temperature and light irradiance for the growth of different microalgae species ranged from $20-30{ }^{\circ} \mathrm{C}$ and $33-400 \mu \mathrm{mol} / \mathrm{m}^{2} / \mathrm{s}$. In another study, Wang et al. (2017) analysed the growth of Neochloris aquatic Cl-M1 in undiluted SW in various temperatures 
$\left(15^{\circ} \mathrm{C}, 25^{\circ} \mathrm{C}, 37^{\circ} \mathrm{C}\right.$ and $\left.40{ }^{\circ} \mathrm{C}\right)$. The maximum biomass concentration $(3.7 \mathrm{~g} / \mathrm{L})$ and maximum carbohydrate content $(33.2 \%)$ were obtained at $25{ }^{\circ} \mathrm{C}$. Therefore, relatively lower and/or higher temperature both demonstrate negative effects on biomass production. One possible explanation is that low temperature could reduce the metabolic rates of microalgae, while high temperatures may trigger oxidative stress (Ali et al., 2005). A positive correlation between biomass production/carbon dioxide fixation and duration hours of the light has been noted by Jacob-Lopes et al. (2009). However, continuously increasing light intensity can damage light receptors after reaching the light saturation point, resulting in photoinhibition (Molinuevo-Salces et al., 2016). Wahidin et al. (2013) in their research obtained maximum cell growth at $100 \mathrm{~mol} / \mathrm{m}^{2} / \mathrm{s}$ and $18 \mathrm{~h}$ light: $6 \mathrm{~h}$ dark cycle for three different light intensities $\left(50,100\right.$ and $\left.200 \mu \mathrm{mol} / \mathrm{m}^{2} / \mathrm{s}\right)$ and three different photoperiod cycles $(24: 0,18: 06$ and 12:12 $\mathrm{h}$ light:dark).

The main cultivation types for microalgae are photoautotrophic cultivation, heterotrophic cultivation and mixotrophic cultivation (Chew et al., 2018). SW with a considerable amount of organic carbon can be used for mixotrophic and heterotrophic growth of microalgae (Wang et al., 2012; Wang et al., 2015). Compared with heterotrophic cultivation condition, mixotrophic cultivation modes result in: firstly, more biomass being produced; and secondly, the accumulation of lipids and carbohydrates (Chew et al., 2018; Wang et al., 2015). The reason could be that the mixotrophic mode combines the advantages of autotrophic cultivation and heterotrophy. Under mixotrophic cultivating conditions, it is suggested that heterotrophic and autotrophic metabolisms happen simultaneously, and microalgae species can grow with organic carbon in $\mathrm{SW}$ and inorganic carbon $\left(\mathrm{CO}_{2}\right)(\mathrm{Chew}$ et al., 2018; Zhan et al., 2017). Wang et al.'s (2015) study concluded that the mixotrophic cultivation of Chlorella vulgaris JSC-6 in diluted SW resulted in higher biomass concentration and carbohydrate content than under heterotrophic cultivation. 


\subsubsection{Impact of toxic contaminants in swine wastewater}

Heavy metals, antibiotics and hormones are usually used in concentrated swine farms worldwide to treat/prevent pig diseases and promote growth (Li et al., 2015; Yost et al., 2014). However, most of these pollutants cannot be completely absorbed by pigs but excreted out from their bodies through faeces and urine, resulting in high concentrations of these pollutants in SW (Cheng et al., 2018b). The concentrations of these pollutants in SW are shown in Fig. 1.

Low levels of trace metal elements are essential for microalgae growth. For instance, $\mathrm{Zn}$ can serve as a co-factor for enzymes participating in $\mathrm{CO}_{2}$ fixation, DNA transcription and phosphorus acquisition (Miazek et al., 2015). Huang et al. (2009) observed that adding Zn at $1.3-2.6 \mathrm{mg} / \mathrm{L}$ can significantly stimulate continuous growth of Chlorella vulgaris. $\mathrm{Cu}$ and $\mathrm{Fe}$ can also serve as components for photosynthetic electron transport proteins for microalgae cells (Miazek et al., 2015). However, high concentrations of heavy metals in SW could adversely affect microalgae growth and consequently reduce the biomass and production of valuable compounds. As reported elsewhere, the sensitivity of microalgae to metals depends on the different concentrations of metals, species of microalgae, and the time of exposure ( $\mathrm{Li}$ et al., 2018). Li et al. (2018) indicated that the growth of microalgae Isochrysis galbana and Coelastrella sp. was inhibited when $\mathrm{Cu}$ concentration increased. Growth stopped and even declined when $\mathrm{Cu}$ concentration was higher than $1.0 \mathrm{mg} / \mathrm{L}$, while lower concentrations $(0.01-$ $0.1 \mathrm{mg} / \mathrm{l})$ causing a gradually tailing off in their growth.

In the same cultivation media, Chlorella vulgaris growth was more influenced by $\mathrm{Cu}$ than the growth of Desmodesmus sp. (Rugnini et al., 2017). Scenedesmus acuminatus also showed greater tolerance to $\mathrm{Cu}$ stress than Chlorella sorokiniana. The reason was that Scenedesmus acuminatus can mitigate the impact of $\mathrm{Cu}$ stress by increasing proline, polyphenols, flavonoids, tocopherols, glutathione levels, as well as the activities of 
glutathione-s-transferase (GST), ascorbate peroxidase (APX), glutathione reductase (GR) and superoxide dismutase (SOD) enzymes (Hamed et al., 2017). Furthermore, under the chronic exposure, microalgae cells were more affected by metals. Mota et al.'s (2015) report indicated that Cyanothece cells reduce their metabolic rate to invest energy in the activation of detoxification mechanisms during chronic exposure to sub-lethal concentrations of $\mathrm{Cu}$, leading to cell death with $0.2 \mathrm{mg} / \mathrm{L}$ of $\mathrm{Cu}$ when exposed for more than one month. The adverse effect of high concentrations of heavy metals on microalgae was due to the accumulation of reactive oxygen species (ROS). The strong oxidative properties of ROS cause severe damage to cellular components, through oxidizing lipids, increasing MDA level, and increasing the rate of mutagenesis. These factors ultimately lead to programmed cell death (Choudhary et al., 2007; Olivares et al., 2016). Consequently, the heavy metals' inhibition of microalgae grow in SW needs more attention paid to it, considering the high concentrations of $\mathrm{Cu}$ and $\mathrm{Zn}$ in SW (up to $14.2 \mathrm{mg} / \mathrm{L}$ and $39 \mathrm{mg} / \mathrm{L}$, respectively).

Even though microalgae are not the target group of antibiotics, high levels of antibiotics in SW can still inhibit microalgae growth. The explanation for this is that microalgae have the same origin as prokaryotes, including chloroplasts and mitochondria (Sendra et al., 2018). Antibiotics can affect the photosynthesis of microalgae by inhibiting chloroplast ribosomes where the similarities between the ribosomal RNA of bacteria and chloroplasts are considered. In the same way, mitochondria can also be affected by antibiotics by inhibiting mitochondrial protein synthesis, which is implicated in electron transport (Halling-Sørensen, 2000; Sendra et al., 2018).

In fact the inhibitory effect of tetracycline antibiotics on microalgae has been documented in previous reports (Fu et al., 2017). Pomati et al. (2004) stated that the growth of Synechocystis fell by 20-22\% at tetracycline (TC) concentration of 10 and $100 \mu \mathrm{g} / \mathrm{L}$, but no negative effect on growth was seen at $1000 \mu \mathrm{g} / \mathrm{L}$. These authors explained that the high 
TC concentration may have induced the production of exoenzymes and consequently converted the antibiotic into broken-down molecules that had a subtle influence on Synechocystis growth. In contrast, Li et al. (2016) found that TC concentrations of $0-0.25$ $\mathrm{mg} / \mathrm{L}$ were expected to have a significant effect on the growth and nutrient removal of Chlamydomonas reinhardtii. Xiong et al. (2018b) indicated that the generation of microalgae biomass might not be affected by TC at low concentration $(\leq 150 \mu \mathrm{g} / \mathrm{L})$, but was inhibited significantly when TC rose to $20 \mathrm{mg} / \mathrm{L}$.

Sulfonamide antibiotics (SAs) have been reported to inhibit algae growth by influencing chlorophyll biosynthesis (Ferrari et al., 2004). Sulfamethoxazole (SMX) at the concentration of $1.0 \mathrm{mg} / \mathrm{L}$ affected the growth of Selenastrum capricornutum through inhibiting the physiological processes of primary photochemistry, electron transport, photophosphorylation and carbon assimilation (Liu et al., 2011). The growth of Chlorella vulgaris was inhibited by sulfamonomethoxine (SMN) at all studied concentrations $(2.5,5,10,15$, and $20 \mathrm{mg} / \mathrm{L})$, while the $72 \mathrm{~h}$ median effective concentration (EC50) value was $5.9 \mathrm{mg} / \mathrm{L}$ (Huang et al., 2014). Under the same cultivation culture, SMX exerted a greater inhibition on the growth of Scenedesmus obliquus than sulfamethazine (SMZ). Specifically, a negligible influence on the growth of Scenedesmus obliquus was observed for both of them at concentrations $\leq 0.5 \mathrm{mg} / \mathrm{L}$, while the adverse effects increased significantly under high concentrations of SMZ (1$6 \mathrm{mg} / \mathrm{L})$ and $\mathrm{SMX}(0.075-0.2 \mathrm{mg} / \mathrm{L})$. The results were, respectively, $34.6-89.0 \%$ and $25.7-$ 83.0\% growth inhibition (Xiong et al., 2018a).

Hormones, including estrone (E1), 17b-estradiol (E2) and 17a-ethinylestradiol (EE2) can adversely affect organisms by altering the endocrine system's normal functioning (Sumpter \& Johnson, 2005). The presence of EE2 (4-8 $\mu \mathrm{g} / \mathrm{L})$ in wastewater affected the microalgae growth and biomass production by inhibiting algae cell division and reducing photosynthesis in algal cells (Balina et al., 2015). The study by de Sá Salomão et al. (2014) 
stated the toxic impact of E1, E2 and EE2 on microalgae species, wherein EE2 and E2 were more toxic than $\mathrm{E} 1$. Yet the authors found that the $\mathrm{EC}_{50}$ of all tested estrogens decreased with cultivation time. Hom-Diaz et al. (2015) also found that the total biomass production of Selenastrum capricornutum and Chlamydomonas reinhardtii cultivated in the culture with the addition of E2 and EE2 was similar with control conditions without hormones.

The gradual decrease in toxicity of hormones might be caused by adsorption and their biodegradation-related removal by algae cells. Zhang et al. (2014) observed that the final biomass concentrations were not significantly affected by even relatively high estrogen concentrations $(100 \mu \mathrm{g} / \mathrm{L})$. The large removals of E1, E2 and EE2 from wastewater by microalgae through adsorption onto the algae biomass and biodegradation are reported in other studies (Hom-Diaz et al., 2015; Shi et al., 2010). Hence, more analyses are required to investigate the correlation between microalgae and these toxic pollutants. Furthermore, the toxicity of antibiotics and hormones to microalgae could be influenced by cultivation conditions and other types of toxicants in SW, for instance the combined effects of different classes of antibiotics and heavy metals in SW (Liu et al., 2018b).

\subsubsection{Impact of bacteria in swine wastewater}

As summarized in Table $1, \mathrm{SW}$ is usually required for pretreatment by autoclaving to avoid the bacteria inhibiting the growth of microalgae. Filzgerald's (1969) report demonstrated that sterilizing the wastewater through an autoclave enabled the survival and growth of microalgae in comparison to little or no growth in raw or untreated samples. Zhang et al. (2012) stated that the microalgae biomass productivity, total lipid content and production rates fell slightly when bacteria coexisted with algae. Similarly, the growth of Chlorella pyrenoidosa in SW subjected to autoclaving was $10.4 \%$ higher than that in the wastewater subjected to ozonation pretreatment, due to the residual bacteria in ozonated SW (Gan et al., 2014). Hence, the present bacteria in SW might undermine or compromise the 
growth of microalgae. On one hand, bacteria in SW could compete with microalgae for organic matter and essential nutrients, and/or might release toxic compounds and thereby partially inhibit algal growth rates (Pittman et al., 2011). On the other hand, microalgae photosynthesis could be restrained by the coexistence of bacteria, because the light intensity transmitted to microalgae could be inhibited by the attached bacteria films to the inner wall of the photo-bioreactor (Gan et al., 2014).

However, the presence of bacteria in wastewater was also possible to promote the microalgae growth and production of valuable compounds through certain complex mechanisms and nutrient exchange (Fuentes et al., 2016; Toyama et al., 2018). Specifically, Toyama et al. (2018) observed the growth of microalgae in wastewater with indigenous bacteria was superior than that without bacteria. Compared to the cultivation in axenic cultures, biomass production of three microalgae - Chlamydomonas reinhardtii, Chlorella vulgaris and Euglena gracilis - increased $>1.5,1.8-2.8$, and $>2.1$-fold, respectively. Xue et al. (2018) also reported an increase in the microalgae biomass and quality of biodiesel in the microalgae-bacterial co-culture system. The reason might be that bacteria could supply inorganic nutrients and other metabolic compounds, such as vitamins, hormones, and EPS (extracellular polymeric substances), to promote microalgae growth (Jia \& Yuan, 2016). Fuentes et al. (2016) wrote that promoting factors, like indole-3-acetic acid and Vitamin $\mathrm{B}_{12}$ produced by bacteria in algal cultures contributed to the faster growth of microalgae. Vitamin $\mathrm{B}_{12}$ is required for the proper functioning of an isoform of methionine synthase enzyme of microalgae; however, many microalgae are auxotrophic for certain vitamins (Croft et al., 2005; Luo \& Moran, 2014). However, this mechanism is not universal for all species of microalgae and bacteria; there are in fact different correlations for different species (Jia \& Yuan, 2016). Thus, to enhance the efficiency of microalgae biomass production and 
associated valuable compounds, more and long-term studies on bacteria effects on the growth of microalgae need to be done (Toyama et al., 2018).

\section{SW purification by harvesting microalgae}

High concentrations of organic matter, nutrients and toxic contaminants in SW have raised many concerns over their adverse effects on the environment and people's health (Cheng et al., 2018b). Various technologies have been developed for removing these pollutants from SW (Cheng et al., 2018b; Wen et al., 2017). Compared with conventional activated sludge and /or anaerobic treatment processes of SW, microalgae-based wastewater treatment systems have advantages of low energy requirements, little sludge formation, reduction of greenhouse emissions and productive use of wastewater. Not only can they effectively remove organic matter, nutrients and toxic pollutants, but they can also recover nutrients. They do this by harvesting biomass and then converting the biomass into valuable bioenergy (Cai et al., 2013). Subsequently, microalgae-based technologies represent a reliable and sustainable alternative strategy for SW treatment.

\subsection{Removal of nutrients}

Carbon, nitrogen and phosphate are important sources of nutrients required for the growth of microalgae. Inorganic nitrogen, including ammonium $\left(\mathrm{NH}_{4}{ }^{+}\right)$, nitrate $\left(\mathrm{NO}_{3}{ }^{-}\right)$and nitrite $\left(\mathrm{NO}_{2}^{-}\right.$), and organic nitrogen (urea and amino acids) in SW are required by microalgae for synthesis of proteins, nucleic acid, enzymes, chlorophylls, and genetic material (Cao et al., 2018). Phosphorus is also a key factor in the energy metabolism of algae and is found in nucleic acids, lipids, proteins, and the intermediates of carbohydrate metabolism (Cai et al., 2013). Hence, TN and TP in SW can be reduced by microalgae via uptake (Xu et al., 2015). It is also evident that the removal of TN and TP is partly due to abiotic processes, such as chemical precipitation and ammonia stripping at high pH (Cai et al., 2013; Luo et al., 2016). Carbon is also indeed a source for microalgae growth, either by direct uptake or 
conversion of carbonate to free carbon dioxide through carbon anhydrase activity (Cai et al., 2013; Wang et al., 2012). COD removal is mainly achieved through biological assimilation of microalgae photosynthesis (Ji et al., 2013b; Munoz \& Guieysse, 2006; Wang et al., 2012). Therefore, microalgae play a key role in removing nutrients from SW in order to prevent the eutrophication and pollution of aquatic environments (Cai et al., 2013). Several previous studies have confirmed that the cultivation of microalgae in SW is efficient for nutrients removal, and the maximum removal efficiency of nutrients and ranges of COD removal by different species of microalgae are depicted in Fig. 2 (a, b) (Abou-Shanab et al., 2013; Deng et al., 2018; Franchino et al., 2016; Luo et al., 2016; Wang et al., 2015; Wen et al., 2017; Zhu et al., 2013b).

Under different cultivation conditions, different species of microalgae demonstrated a wide range of nutrients and COD removal efficiencies, with $>90 \% \mathrm{NH}_{4}-\mathrm{N}, 12.5-90 \% \mathrm{TN}$, $28-97 \%$ TP and $21-80 \%$ COD. $\mathrm{NH}_{4}-\mathrm{N}$ has been reported as the main form of inorganic nitrogen in SW (Wen et al., 2017). The efficiency of removing $\mathrm{NH}_{4}-\mathrm{N}$ by microalgae is relatively higher than the TN removal efficiency. One reason for this may be that algae preferred ammonium to nitrate and nitrite for assimilation until the ammonium was almost completely consumed (Maestrini et al., 1986). For example, Ji et al. (2013b) indicated that the amount of $\mathrm{NH}_{4}-\mathrm{N}$ uptake by Chlorella vulgaris ranged between 6.3 and $42.4 \mathrm{mg} / \mathrm{L}$, which was always higher than the uptake of nitrate $(0.2-19.2 \mathrm{mg} / \mathrm{L})$ and nitrite $(2.3-15.7 \mathrm{mg} / \mathrm{L})$. Similarly, the uptake of $\mathrm{NH}_{4}-\mathrm{N}(24-49 \mathrm{mg} / \mathrm{L})$ by Scenedesmus obliquus resulted in an amount higher than nitrate (3.6-26 mg/L) (Ji et al., 2013a).

Essentially, in the assimilation of inorganic nitrogen, all forms of inorganic nitrogen are ultimately reduced to ammonium prior to being incorporated into amino acids within the intracellular fluid. In this way, ammonium can be used to form amino acids directly without a redox reaction, and it requires less energy (Cai et al., 2013). By contrast, COD revealed 
relatively low uptake efficiency by microalgae compared to inorganic nutrients. The dissolved COD concentration even increases during the incubation in one previous report (Marjakangas et al., 2015). The reason is that during the cultivation stage, microalgae can release significant amounts of carbon to the surroundings, which may potentially increase the COD level of wastewater (Vandamme et al., 2012).

The removal efficiency of nutrients from SW showed a high correlation with microalgae growth. A higher growth rate of the microalgae led to higher removal efficiencies of $\mathrm{NH}_{4}-\mathrm{N}$ and TP (Ji et al., 2013b). Ji et al.'s (2013b) study indicated that $\mathrm{NH}_{4}-\mathrm{N}$ and TP were converted to algal biomass through metabolic pathways to a much greater extent than when removed as inorganic precipitates. Thus, factors influencing the growth of microalgae, such as initial nutrient concentrations, operating conditions and hazardous contaminants in SW, can also affect the removal of nutrients by cultivating microalgae. For instance, a suitable dilution rate of SW is necessary for the effective removal of $\mathrm{NH}_{4}-\mathrm{N}$ and TP. For the culture media with high initial nutrients, the amount of $\mathrm{NH}_{4}-\mathrm{N}, \mathrm{TN}$ and $\mathrm{TP}$ taken up by the microalgae rose when dilution of wastewater was greater (Franchino et al., 2016; Ji et al., 2013b). Wen et al. (2017) stated that the highest removal ratios of COD (58.39\%), TN and TP ( $>90 \%)$ were achieved in $40 \%$ diluted SW, which proved to be higher than that in $20 \%$, $60 \%, 80 \%$ diluted and undiluted wastewater.

Additionally, the microalgae cultivation condition affected the nutrients removal efficiency significantly. Cao et al. (2018) concluded that the concentrations of $\mathrm{NH}_{4}-\mathrm{N}$ and TN declined from 338.02 and $598.04 \mathrm{mg} / \mathrm{L}$ to $152.41,135.55,116.63$ and $371.91,312.31$, $280.12 \mathrm{mg} / \mathrm{L}$ at $\mathrm{pH} 4.0,5.0$, and 6.0, respectively. Increasing $\mathrm{pH}$ in cultures could promote phosphorus precipitation and elevate phosphate adsorption on microalgae cells (Luo et al., 2016). High concentrations of $\mathrm{Ca}^{2+}$ or $\mathrm{Mg}^{2+}$ in $\mathrm{SW}$ are more conducive to phosphate chemical precipitation (Xu et al., 2014). As discussed in section 2.2.2, mixotrophic cultivation is the 
most preferred scenario for microalgae biomass production. The largest amounts of $\mathrm{NH}_{4}-\mathrm{N}$ and TP removal were also obtained under mixotrophic cultivation (Wang et al., 2015).

Removal ratios of $\mathrm{NH}_{4}-\mathrm{N}$ and $\mathrm{TP}$ were adversely affected by increasing heavy metals' concentrations in the culture media. Li et al. (2018) demonstrated that the efficiency in removing $\mathrm{NH}_{4}-\mathrm{N}$ declined from $80 \%$ to $61.6 \%, 58.8 \%, 45.1 \%, 50.7 \%$ and $38.6 \%$, respectively, when the concentration of $\mathrm{Cu}$ rose to $0.10,0.50,1.0,2.0$ and $3.0 \mathrm{mg} / \mathrm{L}$. The removals of TP were $79.0 \%, 70.5 \%, 84.9 \%, 18.2 \%, 28.2 \%$ and $12.6 \%$ with the concentrations of $\mathrm{Cu}$ at $0.0,0.10,0.50,1.0,2.0$ and $3.0 \mathrm{mg} / \mathrm{L}$, respectively. Bacteria in unsterilized culture systems also may contribute to the removal of nutrients from SW (Zhu et al., 2013b). Microalgae in the culture can provide $\mathrm{O}_{2}$ and certain extracellular compounds for aerobic bacteria to biodegrade organic pollutants (Liu et al., 2012; Munoz \& Guieysse, 2006). However, as noted in section 2.2.4, the interactions between bacteria and algae are complicated, so further studies are required.

\subsection{Removal of toxic contaminants}

Heavy metals, antibiotics and hormones in SW are major environmental problems on account of their toxicity and persistence, which means they pose dangers to the ecosystem and human health (Yi et al., 2011). Microalgae have been frequently considered as promising sources for removing these hazardous contaminants due to their ability to grow when high levels of such toxicants and capacities are present; these can be removed effectively (Markou et al., 2018; Norvill et al., 2016). Based on previous reports, the maximum removal efficiencies of these toxicants by different species of microalgae are summarized in Fig. 2 (c, d) (Bai \& Acharya, 2016; de Godos et al., 2012; Hom-Diaz et al., 2015; Norvill et al., 2017; Santaeufemia et al., 2016; Sekomo et al., 2012; Shi et al., 2010; Yang et al., 2017; Zhang et al., 2014). The wide range for heavy metals removal (29-98\%) and antibiotics and hormones removal (32-100\%) from wastewater by microalgae can be attributed to various influential 
parameters. These include, for example, microalgae species, cultivation conditions, species and concentrations of toxicants, $\mathrm{pH}$, and co-existing ions in wastewater (Markou et al., 2018; Yang et al., 2017).

The removal of trace metals by microalgae occurs through a combined process of adsorption and bioaccumulation (Sekomo et al., 2012; Yang et al., 2017). The metal ions are passively adsorbed on the cell surface in the first few seconds or minutes, and subsequently transported slowly inside the cell membrane and are accumulated intracellularly (Markou et al., 2018). A rapid adsorption and bioaccumulation of heavy metals by microalgae has been observed in Cheng et al.'s (2017) research. They showed that the metal concentrations $\left(\mathrm{Zn}^{2+}\right.$, $\mathrm{Cu}^{2+}$, and $\mathrm{Fe}^{2+}$ ) decreased sharply after only 2 days of Chlorella cultivation, with the high removal percentages of $\mathrm{Zn}^{2+}(65.71 \%), \mathrm{Cu}^{2+}(53.64 \%)$, and $\mathrm{Fe}^{2+}(58.89 \%)$. Rugnini et al. (2017) concluded that green microalgae Chlorella vulgaris and Desmodesmus sp were efficient and economical biosorbents for bioremediation of metal-polluted waters. Up to $43 \%$ and 39\% for $\mathrm{Cu}$ were removed by Desmodesmus sp. and C. vulgaris, respectively. As well, $\mathrm{Cu}$ removal by Chlorella vulgaris increased from $43 \%$ to $90 \%$ when Ni was also present in the culture, which may have resulted from the increased synthesis of phytochelatins in the mixed solutions compared to the single metal solutions. Thus the bioaccumulation removal efficiency of $\mathrm{Cu}$ was improved. Metal ions required to bind to chelating proteins are described as phytochelatins and then enter the cell by endocytosis (Kumar et al., 2015).

As shown in Fig. 2, removal of heavy metals by algae varied among different microalgae species. The mainly reason is that the first barrier for biosorption of heavy metals is algae cell walls, the abundance and composition of the electrostatic parameters of the cell walls, mainly polysaccharides and proteins, which governed the microalgae sorption capacities (Rossi \& De Philippis, 2016). Therefore, different species of microalgae and cultivation conditions induced different stresses on the algae which could affect the sorption 
and uptake of heavy metals (Markou et al., 2018). Concentrations of heavy metals in wastewater also affected their uptake by microalgae. Sekomo et al. (2012) indicated that poor efficiency in removing $\mathrm{Cu}$ was obtained under high initial concentrations; specifically, only $29 \%$ of $\mathrm{Cu}$ was removed in the duckweed and the algal ponds with the initial concentration of $1.5 \mathrm{mg} / \mathrm{L}$. Such a low removal efficiency was due to the toxic effects of $\mathrm{Cu}$ on the growth of microalgae, as discussed in section 2.2.3. The level of $\mathrm{pH}$ in the culture can be increased due to the release of $\mathrm{OH}^{-}$ions via uptake of $\mathrm{CO}_{2}$ from bicarbonate during the photosynthesis process of microalgae in culture media (Massé et al., 2014). On one hand, increased pH in the culture media can favor the binding of metal cations on the surface of algae cells; on the other hand, complexation and co-precipitation might occur between metal ions and the co-existing compounds in SW, which decreases the availability of heavy metals for uptake by microalgae (Markou et al., 2018). Therefore, the impact of high pH on heavy metals' uptake by microalgae requires further analysis

Mechanisms of sorption, biodegradation, and photodegradation have been reported as high potential removal mechanisms of antibiotics and hormones from wastewater by microalgae (Norvill et al., 2016). Of these mechanisms, sorption onto biomass contributed less to the overall removal of antibiotics and hormones by microalgae (de Godos et al., 2012; Norvill et al., 2017). As indicated by Norvill et al. (2017), sorption accounted for less than $6 \%$ of the total removal of tetracycline in algae ponds, despite the sorption dominated removal of tetracycline in the absence of light. Zhang et al. (2014) observed that estrogens including 17ß-estradiol, estrone, and estriol, can be removed in large quantities (nearly 95\%) from wastewater by Scenedesmus dimorphus, while sorption makes only a minor contribution to overall apparent removal (4-9\%). According to Shi et al.'s (2010) report, although E1, E2, and EE2 can be quickly adsorbed on algae or duckweed, the adsorbed estrogens are subsequently degraded by microorganisms, algae, or duckweed in the wastewater treatment 
system. According to Norvill et al. (2016), the sorption removal of estrogens onto algae biomass was only visible under high initial concentrations (e.g., $5 \mathrm{mg} / \mathrm{L}$ ), while the amount removed was less than $10 \%$ under low pollutant concentration. The value of $\mathrm{pH}$ and the amount/composition of EPS in algal ponds may affect the algaes' ability to absorb antibiotics and hormones.

Pollutants can be biodegraded by algae via heterotrophic metabolism (Norvill et al., 2016). Santaeufemia et al. (2016) discovered that high removal efficiency (97\%) of oxytetracycline (OTC) was achieved by the microalga Phaeodactylum tricornutum with an initial OTC concentration of $2.5 \mathrm{mg} / \mathrm{L}$, and the removal was due more to bioremediation than photodegradation. Shi et al. (2010) demonstrated that E1, E2, and EE2 can be effectively removed from the continuous-flow algae pond even when their concentrations are at ng/L level, and the removal by biodegradation accounted for $52-56 \%$ in 6 -day batch tests using synthetic wastewater. Large removal of 2 and EE2 (60-95\%) by cultivating Selenastrum capricornutum and Chlamydomonas reinhardtii in wastewater has also been observed by Hom-Diaz et al. (2015), although only $20-54 \%$ of this removal was attributed to biodegradation. The long hydraulic retention time (HRT) operation of algal ponds may enable biodegradation to occur by allowing enough time for deconjugation.

Although photodegradation is negligible for the removal of antibiotics and hormones during conventional wastewater treatment processes, it may well be the dominant removal mechanism during the mixotrophic cultures of microalgae. Their operation relies upon solar energy for photosynthesis (Hom-Diaz et al., 2015). Norvill et al. (2016) and Norvill et al. (2017) both stated that photodegradation was the dominant TC removal mechanism when sunlight exposure in high rate algal ponds. The minimal removal of SMX was also caused by algae-mediated photolysis because algal uptake did not contribute to the removal of the hydrophilic compound (Bai \& Acharya, 2016). Direct photolysis does not make an 
appreciable contribution to the overall removal compared to indirect photodegradation, because of the strong attenuation of light in wastewater (Zhang et al., 2014).

During indirect photolysis, another dissolved organic matter in wastewater can absorb light energy and generate reactive oxygen species, which may subsequently degrade the target pollutants (Norvill et al., 2016). Norvill et al. (2017) found that the rate of TC photodegradation in the wastewater with active biomass was 7 times greater than the control due to the occurrence of indirect photodegradation. Reactive oxygen species were thought to be the main reason for the photodegradation of EE2 and E2 by microalgae Chlorella vulgaris, Anabaena cylindrica and Microcytis aeruginosa kutz (Ge et al., 2009). High light irradiance can increase the strength of photosynthesis, causing the increase of $\mathrm{pH}$ and DO. Higher light intensity, $\mathrm{pH}$ and $\mathrm{DO}$ have been reported to increase the photodegradation removal of antibiotics (Norvill et al., 2017). However, the leaching of these toxicants from algae ponds may lead to contamination of ground water, which become a high risk to human health.

\section{Bioenergy production potential by harvesting microalgae from swine wastewater}

A number of studies have confirmed that microalgae can be used as feedstock for biofuel production, including biodiesel, biomethane and biohydrogen (Kadir et al., 2018; Wieczorek et al., 2014). The creation of biofuel from microalgae has garnered much attention due to the rising energy demand worldwide, and the need to greatly reduce greenhouse gas emissions into the atmosphere (Udaiyappan et al., 2017). Microalgae harvested from SW exhibit favorable properties for biofuel production due to its tolerance and high growth rate in SW, as well as high lipid and carbohydrate content.

\subsection{Biodiesel production potential}

Biodiesel is a mixture of long chain fatty acid methyl esters (FAME) and is obtained by the transesterification of lipids (Zhu et al., 2013b). The economic feasibility of microalgae in biodiesel production, the technology for microalgae harvest from wastewater, lipid extraction 
and biomass pretreatment before biodiesel conversion, have all been comprehensively discussed (Chen et al., 2018; Fazal et al., 2017; Kadir et al., 2018; Mathimani \& Mallick, 2018; Sivaramakrishnan \& Incharoensakdi, 2017; Tan et al., 2017). The previous review indicated that fast growth, high lipid productivity and suitable fatty acid composition of microalgae are essential in biodiesel production. Ranges of lipid content and lipid productivities in different microalgae species from SW are given in Fig. 3 (a, b). The values ranged from $21-46 \%$ and $130-1100 \mathrm{mg} / \mathrm{L} / \mathrm{d}$, respectively, which is comparable with the common lipid content comprising 4-22\% (Abou-Shanab et al., 2013; Amini et al., 2016; Deng et al., 2018; Perazzoli et al., 2016; Wang \& Yin, 2018; Wang et al., 2015; Zhu et al., 2013b). The lipid content of microalgae which was cultivated in SW increased 1.5- to 2-fold compared with that cultivated in culture medium alone (Kuo et al., 2015). Thus, SW can be used for lipid production. Among these studied microalgae species, Chlorella with high lipid content and productivity seems to be a good option for growing in SW and biodiesel production.

The lipid content of microalgae declined as nutrient concentrations rose in the culture media. For example, in the culture with the initial COD concentration at 400 and $800 \mathrm{mg} / \mathrm{L}$, the highest lipid content of Chlorella zofingiensis was $45.81 \%$ and $42.16 \%$ of the dry weight, which decreased to $33.91 \%$ with the increase of initial COD concentration to 3500 mg/L (Zhu et al., 2013b). Wang et al. (2012) concluded that the lipid content in diluted piggery wastewater samples with TN content of 73.5 and $98.0 \mathrm{mg} / \mathrm{L}$ (corresponding to 750 and $1000 \mathrm{mg} / \mathrm{L}$ COD samples, respectively) was significantly less than the $250 \mathrm{mg} / \mathrm{L} \mathrm{COD}$ sample. Feng et al. (2011b) indicated that limited amounts of $\mathrm{N}$ and $\mathrm{P}$ in wastewater could enhance the accumulation of lipid content from microalgae cultivation. Zhu et al. (2013a) showed that nutrient-limited cultures witnessed much higher lipid content (41.21-46.21\% of dry weight) than nutrient-full cultures ( $26 \%$ of dry weight). Additionally, the higher lipid 
content might be caused by greater light intensity received by algal cells in more diluted SW, which activated and promoted cellular lipid storage. Rodolfi et al. (2009) and Feng et al. (2011a) both proved that the lipid accumulation (mainly triacylglycerols) can be raised by increasing light intensity.

A positive relationship between lipid productivity and biomass growth was observed (Luo et al., 2016; Zhu et al., 2013b). Thus, suitable amounts of nutrients in wastewater culture are significant for lipid productivity. Wang et al. (2012) suggested that the lipid productivity in SW in continuous culture mode was higher than that in batch culture mode due to the continuous supplementation of nutrients in the continuous mode. As stated by Zhu et al. (2013b), the lipid content of Chlorella zofingiensis in 800 and $400 \mathrm{mg} / \mathrm{L}$ COD culture was high, yet the biomass productivity was limited. This resulted in the lowest lipid productivities in the culture with $400 \mathrm{mg} / \mathrm{L}$ COD due to the limited biomass productivity. Luo et al. (2016) demonstrated that the highest Coelastrella sp. lipid productivity was obtained in $40 \%$ diluted SW, reaching $13.42 \pm 0.04 \mathrm{mg} / \mathrm{L} /$ day although the lipid contents produced in all cultures were roughly at the same level.

The fatty acid profile has been used as a potential indicator of biodiesel quality. Fatty acids with $16-18$ carbon atoms are considered to be the ideal ingredients for biodiesel production because of their properties such as density, viscosity, flash point and heating value, which can enhance the quality of biodiesel (Luo et al., 2016; Tang et al., 2011). As shown in Fig. 3 (c), the $\mathrm{C} 16$ and $\mathrm{C} 18$ series content (70-97.28\% of the total fatty acids) is the dominant composition of fatty acids extracted from microalgae cultivated in SW, which could improve the quality of biodiesel (Huang et al., 2010). Specifically, Ji et al. (2013b) and Deng et al. (2018) indicated that palmitic acid (C16:0), linoleic acid (C18:2) and linolenic acid (C18:3) were the most abundant fatty acid profiles of the harvested Chlorella vulgaris 
from SW, which were in the $23.8-37 \%, 22.0-22.5 \%$ and $23-43 \%$ ranges of total fatty acids, respectively.

The fatty acid compositions of microalgae Coelastrella sp. were also found to mainly consist of $\mathrm{C} 16: 0, \mathrm{C} 18: 2$ and $\mathrm{C} 18: 3$, with $23.8-30.8 \%, 11.9-20.8 \%$ and $40.5-53.8 \%$ of total fatty acid, respectively (Luo et al., 2016). Oleic acid (C18:1n-9), which is an ideal component of biodiesel, accounted for $27 \%, 19 \%$, and $15 \%$ of the total fatty acids in the cultures of Chlamydomonas mexicana, Chlorella vulgaris, and Scenedesmus obliquus, respectively (Abou-Shanab et al., 2013). Thus, microalgae species harvested from SW could have commercial applications as they completely satisfied the specifications of biodiesel, and the two most common quality standards of biodiesel, ASTM D6751 and EN 14214 (Deng et al., 2018).

Similarly, the fatty acid composition of these microalgae species was affected by nutrition levels, environmental factors, and cultivation conditions (Ji et al., 2013b; Kuo et al., 2015). For example, the content of unsaturated fatty acids extracted from Chlorella vulgaris rose from $63 \%$ to $76 \%$ of the total fatty acids because of an increase of wastewater concentration in the culture media (Ji et al., 2013b). The unsaturated FAME for C16:1, C18:2 and C18:3 in cultures with 3500, 2500, 1900, and $800 \mathrm{mg} / \mathrm{LCOD}$ was predominant in the FAME profile, accounting for $57.30 \%, 52.92 \%, 47.12 \%$ and $52.36 \%$. Meanwhile the counterpart in the 1300 and $400 \mathrm{mg} / \mathrm{L} \mathrm{COD}$ cultures shared $41.70 \%$ and $22.62 \%$ of the total FAME (Zhu et al., 2013b).

\subsection{Biomethane and biohydrogen production potential}

The harvested microalgae biomass from SW can also be used as a substrate to generate biomethane and biohydrogen through anaerobic digestion and dark fermentation (Wieczorek et al., 2014). Carbohydrates contained in microalgae (mainly in the form of glucose and some polysaccharides like starch, agar and carrageenan), are ideal feedstock for green gaseous 
biofuel production (Ho et al., 2012). Compared to the general carbohydrate contents in microalgae (10-20\%), large quantities of carbohydrates in the microalgae from SW confirmed their potential for gaseous biofuel production (from $27.6 \%$ to $58.3 \%$, shown in Fig. 3 (d)). Microalgae Chlorella and Scenedesmus may be the favored species for SW treatment and biofuel production due to their fast growth in SW culture and high carbohydrate content (Chen et al., 2013; Wang \& Yin, 2018). Ferreira et al. (2018) compared the growth and biohydrogen generation potential of Scenedesmus obliquus cultivated in various types of wastewater, and concluded that biomass harvested from SW generated the highest biohydrogen yield ( $390 \mathrm{~mL} \mathrm{H}_{2} / \mathrm{g}$ volatile solids) through batch dark fermentation processes with Enterobacter aerogenes. The reason for this could be the high sugar content present in the biomass from SW (36.2\%).

Furthermore, the lipid-extracted microalgae biomass residues from biodiesel production processes mainly consist of carbohydrates and proteins, which are possible substrates for producing anaerobic fermentation (Mata et al., 2010). Conversely, the produced biogas can supply $\mathrm{CO}_{2}$ to encourage microalgae growth and lipid accumulation. Wang et al. (2012) observed the increase of microalgae biomass concentration, productivity and specific growth rate when the $\mathrm{CO}_{2}$ concentration was increased. The reason is that microalgae induced carboxylation and repressed the oxygenase activity of Rubisco under increased $\mathrm{CO}_{2}$ concentrations, leading to superior microalgae photosynthesis. In their research, Ferreira et al. (2018) found that the presence of $\mathrm{CO}_{2}$ could generate higher lipid contents in microalgae from swine and poultry wastewater. Moreover, the produced biogas had to be further purified by removing $\mathrm{CO}_{2}\left(25-60 \%\right.$ in biogas). Srinuanpan et al. (2018) concluded that $>96 \%$ of $\mathrm{CO}_{2}$ was continuously removed from biogas and the $\mathrm{CH}_{4}$ content in the purified biogas was $>98 \%$ through cultivation of oleaginous microalgae. Therefore, combined biodiesel production with 
biogas generation can improve the economic and environmental feasibility of biofuel production operations (González-González et al., 2018).

\section{Future perspectives}

Though SW is considered to be a valuable source for microalgae-based biomass production, high concentrations of nutrients and toxic pollutants could inhibit the microalgae growth. Based on the above discussion, it is obvious that the dilution of SW with water or synthetic media is usually necessary for efficient microalgae biomass production, although an increase in costs is currently unavoidable. Therefore, developing an efficient process allowing algae to grow well in undiluted SW is necessary in the future, considering its feasible and economical application to full-scale wastewater treatment and bioenergy production. To avoid the toxic effects of bacteria on microalgae growth, SW is usually sterilized through autoclaving, which also increases the operational costs and limits the largescale application of microalgae-based systems. As discussed earlier in section 2.2.4, the impact of bacteria on microalgae growth still requires further and long-term investigation. Research is required to establish the minimal inhibitory concentration of toxic contaminants in SW on microalgae growth and nutrient removal, as well as what their combined effects are. Microalgae are effective in removing toxic contaminants from wastewater, but little research has been done on their removal from SW. Moreover, the dominant and preferred mechanism for removing contaminants by microalgae must be further clarified so that the efficiency in removing contaminants is enhanced.

Meanwhile, problems from the cultivation of microalgae in swine wastewater also require further assessment. For example, the volatile organic carbon (VOC) emissions from algae ponds lead to the production of tropospheric ozone $\left(\mathrm{O}_{3}\right)$ and thus they have adverse effects for humans by affecting the respiratory problems. Overall, there are still some 
obstacles limiting the wide application of SW purification and recovering bioenergy via microalgae cultivation in SW, so further research is still required in this field.

\section{Conclusions}

The key conclusions from this review are: (1) cultivating microalgae in $\mathrm{SW}$ is an alternative method for SW treatment and bioenergy production; (2) microalgae can alive and grow well in swine wastewater for biomass production; (3) nutrients and toxic contaminants in SW can be removed effectively from wastewater through harvesting microalgae; and (4) the lipid and carbohydrate contents in microalgae harvested from SW are comparable with the common values, indicating their potential for bioenergy production.

\section{Acknowledgement}

This review research was supported by the Centre for Technology in Water and Wastewater, University of Technology, Sydney (UTS, RIA NGO) and Korean Ministry of Environment as a “Global Top Project”, Project No. 201600220005.

\section{References}

1. Abou-Shanab, R.A., Ji, M.-K., Kim, H.-C., Paeng, K.-J., Jeon, B.-H., 2013.

Microalgal species growing on piggery wastewater as a valuable candidate for nutrient removal and biodiesel production. J. Environ. Manage. 115, 257-264.

2. Ali, M.B., Hahn, E.-J., Paek, K.-Y., 2005. Effects of temperature on oxidative stress defense systems, lipid peroxidation and lipoxygenase activity in Phalaenopsis. Plant Physiol. Biochem. 43 (3), 213-223.

3. Amin, S., 2009. Review on biofuel oil and gas production processes from microalgae. Energy Convers. Manage. 50 (7), 1834-1840. 
4. Amini, H., Wang, L., Shahbazi, A., 2016. Effects of harvesting cell density, medium depth and environmental factors on biomass and lipid productivities of Chlorella vulgaris grown in swine wastewater. Chem. Eng. Sci. 152, 403-412.

5. Bai, X., Acharya, K., 2016. Removal of trimethoprim, sulfamethoxazole, and triclosan by the green alga Nannochloris sp. J. Hazard. Mater. 315, 70-75.

6. Balina, K., Balode, M., Muzikante, L., Blumberga, D., 2015. Impact of synthetic hormone $17 \alpha$-ethinylestradiol on growth of microalgae Desmodesmus communis. Agron. Res. 13 (2), 445-454.

7. Cai, T., Park, S.Y., Li, Y., 2013. Nutrient recovery from wastewater streams by microalgae: status and prospects. Renew. Sustain. Energy Rev. 19, 360-369.

8. Cao, L., Zhou, T., Li, Z., Wang, J., Tang, J., Ruan, R., Liu, Y., 2018. Effect of combining adsorption-stripping treatment with acidification on the growth of Chlorella vulgaris and nutrient removal from swine wastewater. Bioresour. Technol. 263, 10-16.

9. Chen, C.-Y., Zhao, X.-Q., Yen, H.-W., Ho, S.-H., Cheng, C.-L., Lee, D.-J., Bai, F.W., Chang, J.-S., 2013. Microalgae-based carbohydrates for biofuel production. Biochem. Eng. J. 78, 1-10.

10. Chen, J., Li, J., Dong, W., Zhang, X., Tyagi, R.D., Drogui, P., Surampalli, R.Y., 2018. The potential of microalgae in biodiesel production. Renew. Sustain. Energy Rev. 90, $336-346$.

11. Cheng, D., Ngo, H., Guo, W., Chang, S., Nguyen, D., Kumar, M., Du, B., Wei, Q., Wei, D., 2018a. Problematic effects of antibiotics on anaerobic treatment processes in swine wastewater. Bioresour. Technol. 263, 642-653.

12. Cheng, D.L., Ngo, H.H., Guo, W.S., Liu, Y.W., Zhou, J.L., Chang, S.W., Nguyen, D.D., Bui, X.T., Zhang, X.B., 2018b. Bioprocessing for elimination antibiotics and hormones from swine wastewater. Sci. Total Environ. 621, 1664-1682. 
13. Cheng, P., Wang, Y., Liu, T., Liu, D., 2017. Biofilm attached cultivation of chlorella pyrenoidosa is a developed system for swine wastewater treatment and lipid Production. Frontiers in plant science 8, Article: 1594.

14. Chew, K.W., Chia, S.R., Show, P.L., Yap, Y.J., Ling, T.C., Chang, J.-S., 2018. Effects of water culture medium, cultivation systems and growth modes for microalgae cultivation: A review. J. Taiwan Inst. Chem. Eng. 91, 332-344.

15. Choudhary, M., Jetley, U.K., Khan, M.A., Zutshi, S., Fatma, T., 2007. Effect of heavy metal stress on proline, malondialdehyde, and superoxide dismutase activity in the cyanobacterium Spirulina platensis-S5. Ecotoxicol. Environ. Saf. 66 (2), 204-209.

16. Croft, M.T., Lawrence, A.D., Raux-Deery, E., Warren, M.J., Smith, A.G., 2005. Algae acquire vitamin B 12 through a symbiotic relationship with bacteria. Nature 438 (7064), 90.

17. Daliry, S., Hallajsani, A., Mohammadi Roshandeh, J., Nouri, H., Golzary, A., 2017. Investigation of optimal condition for Chlorella vulgaris microalgae growth. Global Journal of Environmental Science and Management 3 (2), 217-230.

18. Danquah, M.K, Pan, S., Yon, L.S., Jun, L.Y., Chye, J.T.T. 2018. Biofuel production from algal biomass. in: Bioenergy and Biofuels, CRC Press, pp. 123-154.

19. de Godos, I., Muñoz, R., Guieysse, B., 2012. Tetracycline removal during wastewater treatment in high-rate algal ponds. J. Hazard. Mater. 229, 446-449.

20. de Sá Salomão, A.L., Soroldoni, S., Marques, M., Hogland, W., Bila, D.M., 2014. Effects of Single and Mixed Estrogens on Single and Combined Cultures of D. subspicatus and P. subcapitata. Bull. Environ. Contam. Toxicol. 93 (2), 215-221.

21. Deng, X., Gao, K., Addy, M., Chen, P., Li, D., Zhang, R., Lu, Q., Ma, Y., Cheng, Y., Liu, Y., 2018. Growing Chlorella vulgaris on mixed wastewaters for biodiesel feedstock production and nutrient removal. J. Chem. Technol. Biotechnol. 93 (9), 2748-2757. 
22. Fazal, T., Mushtaq, A., Rehman, F., Khan, A.U., Rashid, N., Farooq, W., Rehman, M.S.U., Xu, J., 2017. Bioremediation of textile wastewater and successive biodiesel production using microalgae. Renew. Sustain. Energy Rev. 82(3), 3107-3126.

23. Feng, P., Deng, Z., Hu, Z., Fan, L., 2011a. Lipid accumulation and growth of Chlorella zofingiensis in flat plate photobioreactors outdoors. Bioresour. Technol.102 (22), $10577-10584$.

24. Feng, Y., Li, C., Zhang, D., 2011b. Lipid production of Chlorella vulgaris cultured in artificial wastewater medium. Bioresour. Technol. 102 (1), 101-105.

25. Ferrari, B., Mons, R., Vollat, B., Fraysse, B., Paxēaus, N., Giudice, R.L., Pollio, A., Garric, J., 2004. Environmental risk assessment of six human pharmaceuticals: Are the current environmental risk assessment procedures sufficient for the protection of the aquatic environment? Environ. Toxicol. Chem. 23 (5), 1344-1354.

26. Ferreira, A., Marques, P., Ribeiro, B., Assemany, P., de Mendonça, H.V., Barata, A., Oliveira, A.C., Reis, A., Pinheiro, H.M., Gouveia, L., 2018. Combining biotechnology with circular bioeconomy: From poultry, swine, cattle, brewery, dairy and urban wastewaters to biohydrogen. Environ. Res. 164, 32-38.

27. Filzgerald, G.P., 1969. Some factors in the competition or antagonism among bacteria, algae, and aquatic weeds. J. Phycol. 5 (4), 351-359.

28. Franchino, M., Tigini, V., Varese, G.C., Sartor, R.M., Bona, F., 2016. Microalgae treatment removes nutrients and reduces ecotoxicity of diluted piggery digestate. Sci. Total Environ. 569, 40-45.

29. Fu, L., Huang, T., Wang, S., Wang, X., Su, L., Li, C., Zhao, Y., 2017. Toxicity of 13 different antibiotics towards freshwater green algae Pseudokirchneriella subcapitata and their modes of action. Chemosphere 168, 217-222. 
30. Fuentes, J.L., Garbayo, I., Cuaresma, M., Montero, Z., González-del-Valle, M., Vílchez, C., 2016. Impact of microalgae-bacteria interactions on the production of algal biomass and associated compounds. Mar. Drugs 14 (5), 100.

31. Gan, K., Mou, X., Xu, Y., Wang, H., 2014. Application of ozonated piggery wastewater for cultivation of oil-rich Chlorella pyrenoidosa. Bioresour. Technol. 171, 285290.

32. Ge, L., Deng, H., Wu, F., Deng, N., 2009. Microalgae-promoted photodegradation of two endocrine disrupters in aqueous solutions. Journal of Chemical Technology \& Biotechnology: International Research in Process, Environmental \& Clean Technology 84 (3), 331-336.

33. González-González, L.M., Correa, D.F., Ryan, S., Jensen, P.D., Pratt, S., Schenk, P.M., 2018. Integrated biodiesel and biogas production from microalgae: towards a sustainable closed loop through nutrient recycling. Renew. Sustain. Energy Rev. 82, 11371148.

34. Halling-Sørensen, B., 2000. Algal toxicity of antibacterial agents used in intensive farming. Chemosphere 40 (7), 731-739.

35. Hamed, S.M., Selim, S., Klöck, G., AbdElgawad, H., 2017. Sensitivity of two green microalgae to copper stress: Growth, oxidative and antioxidants analyses. Ecotoxicol. Environ. Saf. 144, 19-25.

36. Ho, S.-H., Chen, C.-Y., Chang, J.-S., 2012. Effect of light intensity and nitrogen starvation on $\mathrm{CO} 2$ fixation and lipid/carbohydrate production of an indigenous microalga Scenedesmus obliquus CNW-N. Bioresour. Technol. 113, 244-252.

37. Hodaifa, G., Martínez, M.E., Sánchez, S., 2009. Influence of pH on the culture of Scenedesmus obliquus in olive-mill wastewater. Biotechnol. Bioprocess Eng. 14 (6), 854 860. 
38. Hom-Diaz, A., Llorca, M., Rodríguez-Mozaz, S., Vicent, T., Barceló, D., Blánquez, P., 2015. Microalgae cultivation on wastewater digestate: $\beta$-estradiol and $17 \alpha-$ ethynylestradiol degradation and transformation products identification. J. Environ. Manage. $155,106-113$.

39. Huang, D.-J., Hou, J.-H., Kuo, T.-F., Lai, H.-T., 2014. Toxicity of the veterinary sulfonamide antibiotic sulfamonomethoxine to five aquatic organisms. Environ. Toxicol. Pharmacol. 38 (3), 874-880.

40. Huang, G., Chen, F., Wei, D., Zhang, X., Chen, G., 2010. Biodiesel production by microalgal biotechnology. Appl. Energy 87 (1), 38-46.

41. Huang, Z., Li, L., Huang, G., Yan, Q., Shi, B., Xu, X., 2009. Growth-inhibitory and metal-binding proteins in Chlorella vulgaris exposed to cadmium or zinc. Aquat. Toxicol. 91 (1), 54-61.

42. Jacob-Lopes, E., Scoparo, C.H.G., Lacerda, L.M.C.F., Franco, T.T., 2009. Effect of light cycles (night/day) on $\mathrm{CO} 2$ fixation and biomass production by microalgae in photobioreactors. Chem. Eng. Process: Process Intensification 48 (1), 306-310.

43. Ji, M.-K., Abou-Shanab, R.A., Hwang, J.-H., Timmes, T.C., Kim, H.-C., Oh, Y.-K., Jeon, B.-H., 2013a. Removal of nitrogen and phosphorus from piggery wastewater effluent using the green microalga Scenedesmus obliquus. J. Environ. Eng. 139 (9), 1198-1205. 44. Ji, M.-K., Kim, H.-C., Sapireddy, V.R., Yun, H.-S., Abou-Shanab, R.A., Choi, J., Lee, W., Timmes, T.C., Jeon, B.-H., 2013b. Simultaneous nutrient removal and lipid production from pretreated piggery wastewater by Chlorella vulgaris YSW-04. Appl. Microbiol. Biotechnol. 97 (6), 2701-2710.

45. Jia, H., Yuan, Q., 2016. Removal of nitrogen from wastewater using microalgae and microalgae-bacteria consortia. Cogent Environmental Science 2 (1), Article: 1275089. 
46. Kadir, W.N.A., Lam, M.K., Uemura, Y., Lim, J.W., Lee, K.T., 2018. Harvesting and pre-treatment of microalgae cultivated in wastewater for biodiesel production: A review. Energy Convers. Manage. 171, 1416-1429.

47. Kumar, G., Nguyen, D.D., Sivagurunathan, P., Kobayashi, T., Xu, K., Chang, S.W., 2018. Cultivation of microalgal biomass using swine manure for biohydrogen production: Impact of dilution ratio and pretreatment. Bioresour. Technol. 260, 16-22.

48. Kumar, K.S., Dahms, H.-U., Won, E.-J., Lee, J.-S., Shin, K.-H., 2015. Microalgae-A promising tool for heavy metal remediation. Ecotoxicol. Environ. Saf. 113, 329-352.

49. Kuo, C.-M., Chen, T.-Y., Lin, T.-H., Kao, C.-Y., Lai, J.-T., Chang, J.-S., Lin, C.-S., 2015. Cultivation of Chlorella sp. GD using piggery wastewater for biomass and lipid production. Bioresour. Technol. 194, 326-333.

50. Li, J., Zheng, X., Liu, K., Sun, S., Li, X., 2016. Effect of tetracycline on the growth and nutrient removal capacity of Chlamydomonas reinhardtii in simulated effluent from wastewater treatment plants. Bioresour. Technol. 218, 1163-1169.

51. Li, X., Yang, W.L., He, H., Wu, S., Zhou, Q., Yang, C., Zeng, G., Luo, L., Lou, W., 2018. Responses of microalgae Coelastrella sp. to stress of cupric ions in treatment of anaerobically digested swine wastewater. Bioresour. Technol. 251, 274-279.

52. Li, Y.-R., Tsai, W.-T., Hsu, Y.-C., Xie, M.-Z., Chen, J.-J., 2014. Comparison of autotrophic and mixotrophic cultivation of green microalgal for biodiesel production. Energy Procedia 52, 371-376.

53. Li, Y., Liu, B., Zhang, X., Gao, M., Wang, J., 2015. Effects of Cu exposure on enzyme activities and selection for microbial tolerances during swine-manure composting. J. Hazard. Mater. 283, 512-518. 
54. Liu, B.-Y., Nie, X.-P., Liu, W.-Q., Snoeijs, P., Guan, C., Tsui, M.T., 2011. Toxic effects of erythromycin, ciprofloxacin and sulfamethoxazole on photosynthetic apparatus in Selenastrum capricornutum. Ecotoxicol. Environ. Saf. 74 (4), 1027-1035.

55. Liu, F., Zhang, S., Luo, P., Zhuang, X., Chen, X., Wu, J., 2018a. Purification and reuse of non-point source wastewater via Myriophyllum-based integrative biotechnology: a review. Bioresour. Technol. 248, 3-11.

56. Liu, H., Zhou, Y., Xiao, W., Ji, L., Cao, X., Song, C., 2012. Shifting nutrientmediated interactions between algae and bacteria in a microcosm: Evidence from alkaline phosphatase assay. Microbiol. Res. 167 (5), 292-298.

57. Liu, L., Wu, W., Zhang, J., Lv, P., Xu, L., Yan, Y., 2018b. Progress of research on the toxicology of antibiotic pollution in aquatic organisms. Acta Ecol Sin 38 (1), 36-41.

58. Luo, H., Moran, M.A., 2014. Evolutionary ecology of the marine Roseobacter clade. Microbiol. Mol. Biol. Rev. 78 (4), 573-587.

59. Luo, L., He, H., Yang, C., Wen, S., Zeng, G., Wu, M., Zhou, Z., Lou, W., 2016. Nutrient removal and lipid production by Coelastrella sp. in anaerobically and aerobically treated swine wastewater. Bioresour. Technol. 216, 135-141.

60. Luo, P., Liu, F., Zhang, S., Li, H., Yao, R., Jiang, Q., Xiao, R., Wu, J., 2018. Nitrogen removal and recovery from lagoon-pretreated swine wastewater by constructed wetlands under sustainable plant harvesting management. Bioresour. Technol. 258, 247-254.

61. Maestrini, S.Y., Robert, J.-M., Leftley, J.W., Collos, Y., 1986. Ammonium thresholds for simultaneous uptake of ammonium and nitrate by oyster-pond algae. J. Exp. Mar. Biol. Ecol. 102 (1), 75-98.

62. Marjakangas, J.M., Chen, C.-Y., Lakaniemi, A.-M., Puhakka, J.A., Whang, L.-M., Chang, J.-S., 2015. Selecting an indigenous microalgal strain for lipid production in anaerobically treated piggery wastewater. Bioresour. Technol. 191, 369-376. 
63. Markou, G., Angelidaki, I., Georgakakis, D., 2012. Microalgal carbohydrates: an overview of the factors influencing carbohydrates production, and of main bioconversion technologies for production of biofuels. Appl. Microbiol. Biotechnol. 96 (3), 631-645. 64. Markou, G., Wang, L., Ye, J., Unc, A., 2018. Using agro-industrial wastes for the cultivation of microalgae and duckweeds: Contamination risks and biomass safety concerns. Biotechnol. Adv. 36(4), 1238-1254.

65. Massé, D.I., Saady, N.M.C., Gilbert, Y., 2014. Potential of biological processes to eliminate antibiotics in livestock manure: an overview. Animals 4 (2), 146-163.

66. Mata, T.M., Martins, A.A., Caetano, N.S., 2010. Microalgae for biodiesel production and other applications: a review. Renew. Sustain. Energy Rev. 14 (1), 217-232.

67. Mathimani, T., Mallick, N., 2018. A comprehensive review on harvesting of microalgae for biodiesel-Key challenges and future directions. Renew. Sustain. Energy Rev. $91,1103-1120$.

68. Miazek, K., Iwanek, W., Remacle, C., Richel, A., Goffin, D., 2015. Effect of metals, metalloids and metallic nanoparticles on microalgae growth and industrial product biosynthesis: a review. Int. J. Mol. Sci. 16 (10), 23929-23969.

69. Molinuevo-Sâlces, B., Mahdy, A., Ballesteros, M., González-Fernández, C., 2016. From piggery wastewater nutrients to biogas: Microalgae biomass revalorization through anaerobic digestion. Renewable Energy 96, 1103-1110.

70. Mota, R., Pereira, S.B., Meazzini, M., Fernandes, R., Santos, A., Evans, C.A., De Philippis, R., Wright, P.C., Tamagnini, P., 2015. Effects of heavy metals on Cyanothece sp. CCY 0110 growth, extracellular polymeric substances (EPS) production, ultrastructure and protein profiles. J. Proteomics 120, 75-94.

71. Munoz, R., Guieysse, B., 2006. Algal-bacterial processes for the treatment of hazardous contaminants: a review. Water Res. 40 (15), 2799-2815. 
72. Norvill, Z.N., Shilton, A., Guieysse, B., 2016. Emerging contaminant degradation and removal in algal wastewater treatment ponds: Identifying the research gaps. J. Hazard. Mater. 313, 291-309.

73. Norvill, Z.N., Toledo-Cervantes, A., Blanco, S., Shilton, A., Guieysse, B., Muñoz, R., 2017. Photodegradation and sorption govern tetracycline removal during wastewater treatment in algal ponds. Bioresour. Technol. 232, 35-43.

74. Olivares, H.G., Lagos, N.M., Gutierrez, C.J., Kittelsen, R.C., Valenzuela, G.L., Lillo, M.E.H., 2016. Assessment oxidative stress biomarkers and metal bioaccumulation in macroalgae from coastal areas with mining activities in Chile. Environ. Monit. Assess. 188 (1), 25.

75. Pan, X., Qiang, Z., Ben, W., Chen, M., 2011. Residual veterinary antibiotics in swine manure from concentrated animal feeding operations in Shandong Province, China.

Chemosphere 84 (5), 695-700.

76. Park, J., Jin, H.-F., Lim, B.-R., Park, K.-Y., Lee, K., 2010. Ammonia removal from anaerobic digestion effluent of livestock waste using green alga Scenedesmus sp. Bioresour. Technol. 101 (22), 8649-8657.

77. Perazzoli, S., Bruchez, B.M., Michelon, W., Steinmetz, R.L., Mezzari, M.P., Nunes, E.O., da Silva, M.L., 2016. Optimizing biomethane production from anaerobic degradation of Scenedesmus spp. biomass harvested from algae-based swine digestate treatment. Int. Biodeterior. Biodegrad. 109, 23-28.

78. Pittman, J.K., Dean, A.P., Osundeko, O., 2011. The potential of sustainable algal biofuel production using wastewater resources. Bioresour. Technol. 102 (1), 17-25.

79. Pomati, F., Netting, A.G., Calamari, D., Neilan, B.A., 2004. Effects of erythromycin, tetracycline and ibuprofen on the growth of Synechocystis sp. and Lemna minor. Aquat. Toxicol. 67 (4), 387-396. 
80. Poorter, H., Nagel, O., 2000. The role of biomass allocation in the growth response of plants to different levels of light, $\mathrm{CO} 2$, nutrients and water: a quantitative review. Funct. Plant Biol. 27 (12), 1191-1191.

81. Prandini, J.M., da Silva, M.L.B., Mezzari, M.P., Pirolli, M., Michelon, W., Soares, H.M., 2016. Enhancement of nutrient removal from swine wastewater digestate coupled to biogas purification by microalgae Scenedesmus spp. Bioresour. Technol. 202, 67-75.

82. Qiu, R., Gao, S., Lopez, P.A., Ogden, K.L., 2017. Effects of pH on cell growth, lipid production and CO2 addition of microalgae Chlorella sorokiniana. Algal Research 28, $192-$ 199.

83. Reportlinker. 2017. Global Pork Meat Market 2017-2021, Vol. 2018. https://www.prnewswire.com/news-releases/global-pork-meat-market-2017-2021300537453.html.

84. Rodolfi, L., Chini Zittelli, G., Bassi, N., Padovani, G., Biondi, N., Bonini, G., Tredici, M.R., 2009. Microalgae for oil: Strain selection, induction of lipid synthesis and outdoor mass cultivation in a low-cost photobioreactor. Biotechnol. Bioeng. 102 (1), 100-112.

85. Rossi, F., De Philippis, R. 2016. Exocellular polysaccharides in microalgae and cyanobacteria: chemical features, role and enzymes and genes involved in their biosynthesis. in: The physiology of microalgae, Springer, pp. 565-590.

86. Rugnini, L., Costa, G., Congestri, R., Bruno, L., 2017. Testing of two different strains of green microalgae for $\mathrm{Cu}$ and $\mathrm{Ni}$ removal from aqueous media. Sci. Total Environ. 601, 959-967.

87. Salama, E.-S., Kurade, M.B., Abou-Shanab, R.A., El-Dalatony, M.M., Yang, I.-S., Min, B., Jeon, B.-H., 2017. Recent progress in microalgal biomass production coupled with wastewater treatment for biofuel generation. Renew. Sustain. Energy Rev. 79, 1189-1211. 
88. Santaeufemia, S., Torres, E., Mera, R., Abalde, J., 2016. Bioremediation of oxytetracycline in seawater by living and dead biomass of the microalga Phaeodactylum tricornutum. J. Hazard. Mater. 320, 315-325.

89. Schnurr, P.J., Allen, D.G., 2015. Factors affecting algae biofilm growth and lipid production: a review. Renew. Sustain. Energy Rev. 52, 418-429.

90. Sekomo, C.B., Rousseau, D.P., Saleh, S.A., Lens, P.N., 2012. Heavy metal removal in duckweed and algae ponds as a polishing step for textile wastewater treatment. Ecol. Eng. 44, $102-110$.

91. Sendra, M., Moreno-Garrido, I., Blasco, J., Araújo, C.V., 2018. Effect of erythromycin and modulating effect of $\mathrm{CeO} 2$ NPs on the toxicity exerted by the antibiotic on the microalgae Chlamydomonas reinhardtii and Phaeodactylum tricornutum. Environ. Pollut. $242,357-366$.

92. Shi, W., Wang, L., Rousseau, D.P.L., Lens, P.N.L., 2010b. Removal of estrone, 17 $\alpha-$ ethinylestradiol, and 17ß-estradiol in algae and duckweed-based wastewater treatment systems. Environ. Sci. Pollut. Res. 17 (4), 824-833.

93. Singh, S., Singh, P., 2015. Effect of temperature and light on the growth of algae species: a review. Renew. Sust. Energy Rev. 50, 431-444.

94. Sivaramakrishnan, R., Incharoensakdi, A., 2017. Microalgae as feedstock for biodiesel production under ultrasound treatment-A review. Bioresour. Technol. 250, 877887.

95. Srinuanpan, S., Cheirsilp, B., Prasertsan, P., 2018. Effective biogas upgrading and production of biodiesel feedstocks by strategic cultivation of oleaginous microalgae. Energy $148,766-774$. 
96. Sumpter, J.P., Johnson, A.C., 2005. Lessons from endocrine disruption and their application to other issues concerning trace organics in the aquatic environment. Environ. Sci. Technol. 39 (12), 4321-4332.

97. Tan, X., Lam, M.K., Uemura, Y., Lim, J.W., Wong, C.Y., Lee, K.T., 2017. Cultivation of microalgae for biodiesel production: A review on upstream and downstream processing. Chin. J. Chem. Eng. 26(1), 17-30.

98. Tang, D., Han, W., Li, P., Miao, X., Zhong, J., 2011. $\mathrm{CO}_{2}$ biofixation and fatty acid composition of Scenedesmus obliquus and Chlorella pyrenoidosa in response to different CO2 levels. Bioresour. Technol. 102 (3), 3071-3076.

99. Toyama, T., Kasuya, M., Hanaoka, T., Kobayashi, N., Tanaka, Y., Inoue, D., Sei, K., Morikawa, M., Mori, K., 2018. Growth promotion of three microalgae, Chlamydomonas reinhardtii, Chlorella vulgaris and Euglena gracilis, by in situ indigenous bacteria in wastewater effluent. Biotechnology for biofuels 11 (1), 176.

100. Udaiyappan, A.F.M., Hasan, H.A., Takriff, M.S., Abdullah, S.R.S., 2017. A review of the potentials, challenges and current status of microalgae biomass applications in industrial wastewater treatment. Journal of Water Process Engineering 20, 8-21.

101. Vandamme, D., Foubert, I., Fraeye, I., Muylaert, K., 2012. Influence of organic matter generated by Chlorella vulgaris on five different modes of flocculation. Bioresour. Technol. 124, 508-511.

102. Verma, R., Srivastava, A., 2018. Carbon Dioxide Sequestration and Its Enhanced Utilization by Photoautotroph Microalgae. Environ. Dev. 27, 95-106.

103. Wahidin, S., Idris, A., Shaleh, S.R.M., 2013. The influence of light intensity and photoperiod on the growth and lipid content of microalgae Nannochloropsis sp. Bioresour. Technol. 129, 7-11. 
104. Wang, H., Xiong, H., Hui, Z., Zeng, X., 2012. Mixotrophic cultivation of Chlorella pyrenoidosa with diluted primary piggery wastewater to produce lipids. Bioresour. Technol. $104,215-220$.

105. Wang, J., Yin, Y., 2018. Fermentative hydrogen production using pretreated microalgal biomass as feedstock. Microb. cell fact. 17 (1), 22.

106. Wang, M., Yang, Y., Chen, Z., Chen, Y., Wen, Y., Chen, B., 2016a. Removal of nutrients from undiluted anaerobically treated piggery wastewater by improved microalgae. Bioresour. Technol. 222, 130-138.

107. Wang, Y., Guo, W., Yen, H.-W., Ho, S.-H., Lo, Y.-C., Cheng, C.-L., Ren, N., Chang, J.-S., 2015. Cultivation of Chlorella vulgaris JSC-6 with swine wastewater for simultaneous nutrient/COD removal and carbohydrate production. Bioresour. Technol. 198, 619-625.

108. Wang, Y., Ho, S.-H., Cheng, C.-L., Guo, W.-Q., Nagarajan, D., Ren, N.-Q., Lee, D.J., Chang, J.-S., 2016b. Perspectives on the feasibility of using microalgae for industrial wastewater treatment. Bioresour. Technol. 222, 485-497.

109. Wang, Y., Ho, S.-H., Cheng, C.-L., Nagarajan, D., Guo, W.-Q., Lin, C., Li, S., Ren, N., Chang, J.-S., 2017. Nutrients and COD removal of swine wastewater with an isolated microalgal strain Neochloris aquatica CL-M1 accumulating high carbohydrate content used for biobutanol production. Bioresour. Technol. 242, 7-14.

110. Wen, Y., He, Y., Ji, X., Li, S., Chen, L., Zhou, Y., Wang, M., Chen, B., 2017.

Isolation of an indigenous Chlorella vulgaris from swine wastewater and characterization of its nutrient removal ability in undiluted sewage. Bioresour. Technol. 243, 247-253.

111. Wieczorek, N., Kucuker, M.A., Kuchta, K., 2014. Fermentative hydrogen and methane production from microalgal biomass (Chlorella vulgaris) in a two-stage combined process. Appl. Energy 132, 108-117. 
112. Xiong, J.-Q., Kim, S.-J., Kurade, M.B., Govindwar, S., Abou-Shanab, R.A., Kim, J.R., Roh, H.-S., Khan, M.A., Jeon, B.-H., 2018a. Combined effects of sulfamethazine and sulfamethoxazole on a freshwater microalga, Scenedesmus obliquus: Toxicity, biodegradation, and metabolic fate. J. Hazard. Mater.

113. Xiong, Y., Hozic, D., Goncalves, A.L., Simões, M., Hong, P.-Y., 2018b. Increasing tetracycline concentrations on the performance and communities of mixed microalgaebacteria photo-bioreactors. Algal Research 29, 249-256.

114. Xu, J., Zhao, Y., Zhao, G., Zhang, H., 2015. Nutrient removal and biogas upgrading by integrating freshwater algae cultivation with piggery anaerobic digestate liquid treatment. Appl. Microbiol. Biotechnol. 99 (15), 6493-6501.

115. Xu, M., Bernards, M., Hu, Z., 2014. Algae-facilitated chemical phosphorus removal during high-density Chlorella emersonii cultivation in a membrane bioreactor. Bioresour. Technol. 153, 383-387.

116. Xue, L., Shang, H., Ma, P., Wang, X., He, X., Niu, J., Wu, J., 2018. Analysis of growth and lipid production characteristics of Chlorella vulgaris in artificially constructed consortia with symbiotic bacteria. J. Basic Microbiol. 58 (4), 358-367.

117. Yang, S., Xu, J., Wang, Z.-M., Bao, L.-J., Zeng, E.Y., 2017. Cultivation of oleaginous microalgae for removal of nutrients and heavy metals from biogas digestates. J. Clean. Prod. $164,793-803$.

118. Yi, Y., Yang, Z., Zhang, S., 2011. Ecological risk assessment of heavy metals in sediment and human health risk assessment of heavy metals in fishes in the middle and lower reaches of the Yangtze River basin. Environ. Pollut. 159 (10), 2575-2585.

119. Yost, E.E., Meyer, M.T., Dietze, J.E., Williams, C.M., Worley-Davis, L., Lee, B., Kullman, S.W., 2014. Transport of steroid hormones, phytoestrogens, and estrogenic activity across a swine lagoon/sprayfield system. Environ. Sci. Technol. 48 (19), 11600-11609. 
120. Zhan, J., Rong, J., Wang, Q., 2017. Mixotrophic cultivation, a preferable microalgae cultivation mode for biomass/bioenergy production, and bioremediation, advances and prospect. Int. J. Hydrogen Energy 42 (12), 8505-8517.

121. Zhang, Y., Habteselassie, M.Y., Resurreccion, E.P., Mantripragada, V., Peng, S. Bauer, S., Colosi, L.M., 2014. Evaluating removal of steroid estrogens by a model alga as a possible sustainability benefit of hypothetical integrated algae cultivation and wastewater treatment systems. ACS Sustainable Chemistry \& Engineering 2 (11), 2544-2553.

122. Zhang, Y., Su, H., Zhong, Y., Zhang, C., Shen, Z., Sang, W., Yan, G., Zhou, X., 2012. The effect of bacterial contamination on the heterotrophic cultivation of Chlorella pyrenoidosa in wastewater from the production of soybean products. Water Res. 46 (17), $5509-5516$.

123. Zhu, L., Takala, J., Hiltunen, E., Wang, Z., 2013a. Recycling harvest water to cultivate Chlorella zofingiensis under nutrient limitation for biodiesel production. Bioresour. Technol. 144, 14-20.

124. Zhu, L., Wang, Z., Shu, Q., Takala, J., Hiltunen, E., Feng, P., Yuan, Z., 2013 b. Nutrient removal and biodiesel production by integration of freshwater algae cultivation with piggery wastewater treatment. Water Res. 47 (13), 4294-4302. 


\section{Figure Captions}

Fig. 1 Concentrations of pollutants in SW: (a) COD and nutrients concentrations; (b) Metal concentrations; (c) Average antibiotic concentrations; (d) Average hormone concentrations. Fig. 2 Removal efficiencies of pollutants from wastewater by cultivating different species of microalgae: (a) Maximum nutrient removal efficiencies; (b) COD removal efficiencies; (c) Maximum heavy metal removal efficiencies; (d) Maximum antibiotic and hormone removal efficiencies.

Fig. 3 Chemical composition of different microalgae species harvested from SW: (a) lipid contents; (b) lipid productivities; (c) Total fatty acid composition; (d) Carbohydrate contents.

\section{Table Captions}

Table 1 Microalgae growth and biomass production from swine wastewater (SW) under various cultivation conditions. 
(a)

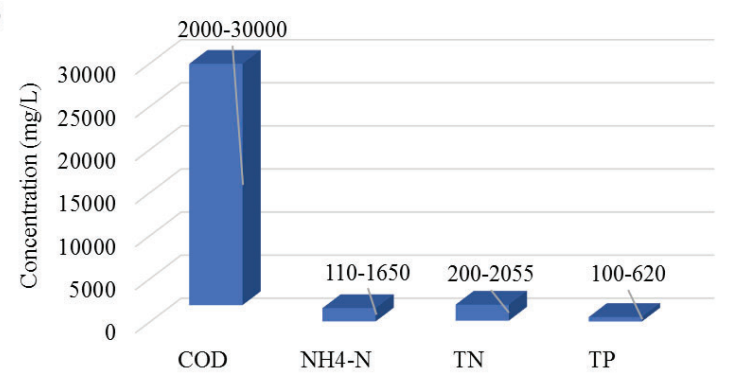

(c)

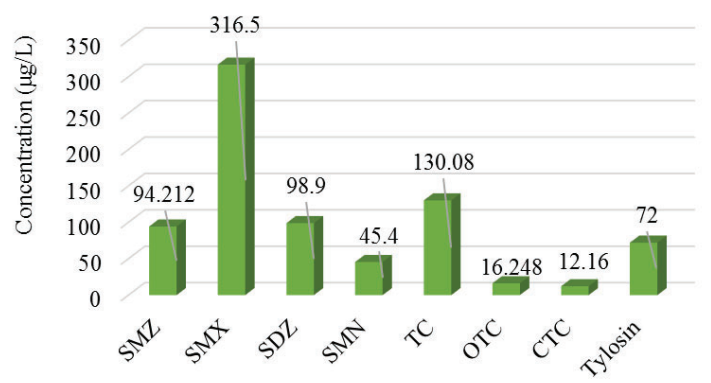

(b)

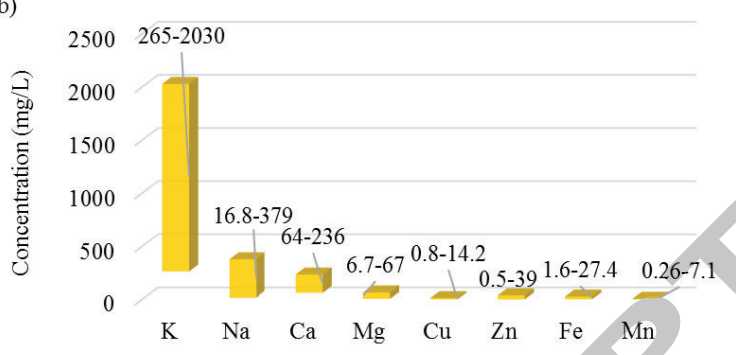

(d)

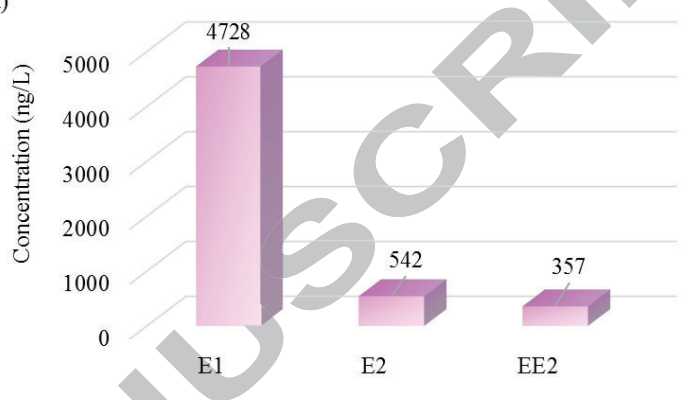

Fig. 1 Concentrations of pollutants in SW: (a) COD and nutrients concentrations; (b) Metal concentrations; (c) Average antibiotic concentrations; (d) Average hormone concentrations. 
(a)

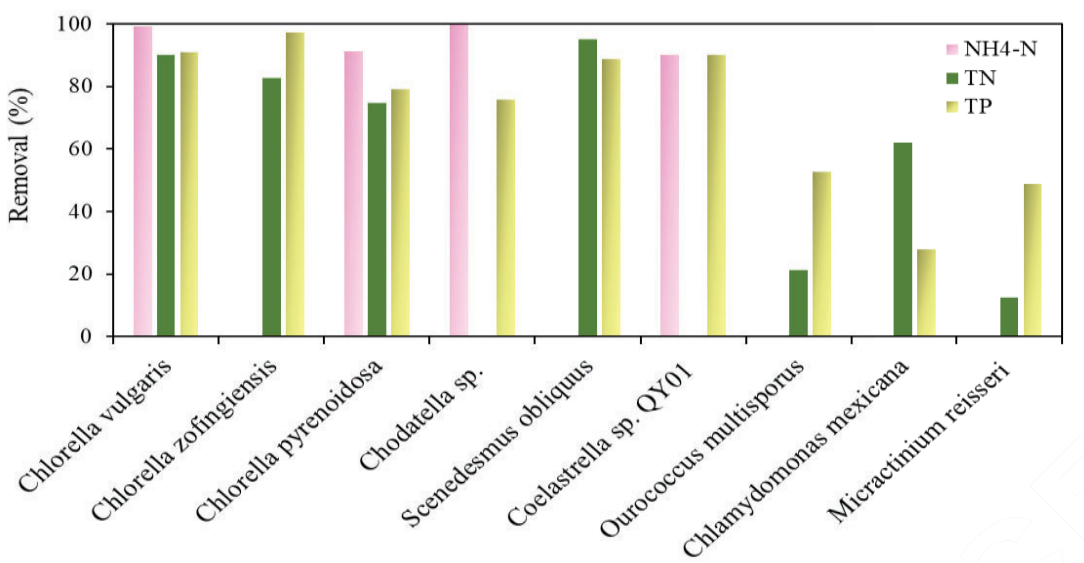

(b)

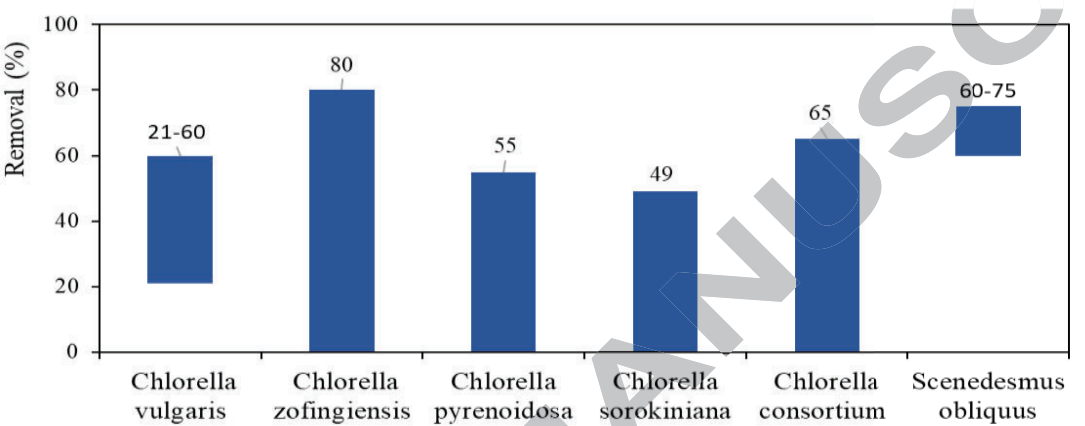

(c)

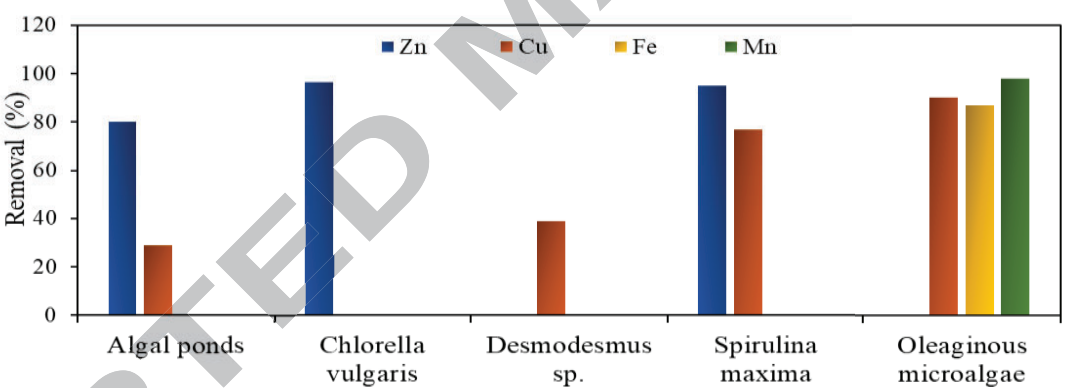

(d)
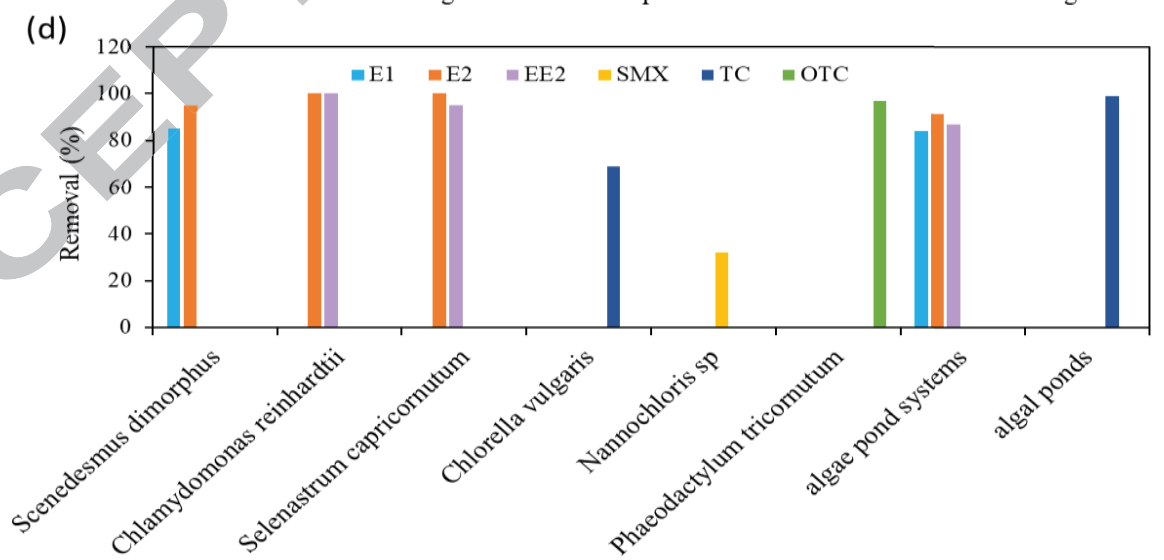

Fig. 2 Removal efficiencies of pollutants from wastewater by cultivating different species of microalgae: (a) Maximum nutrient removal efficiencies; (b) COD removal efficiencies; (c) Maximum heavy metal removal efficiencies; (d) Maximum antibiotic and hormone removal efficiencies. 

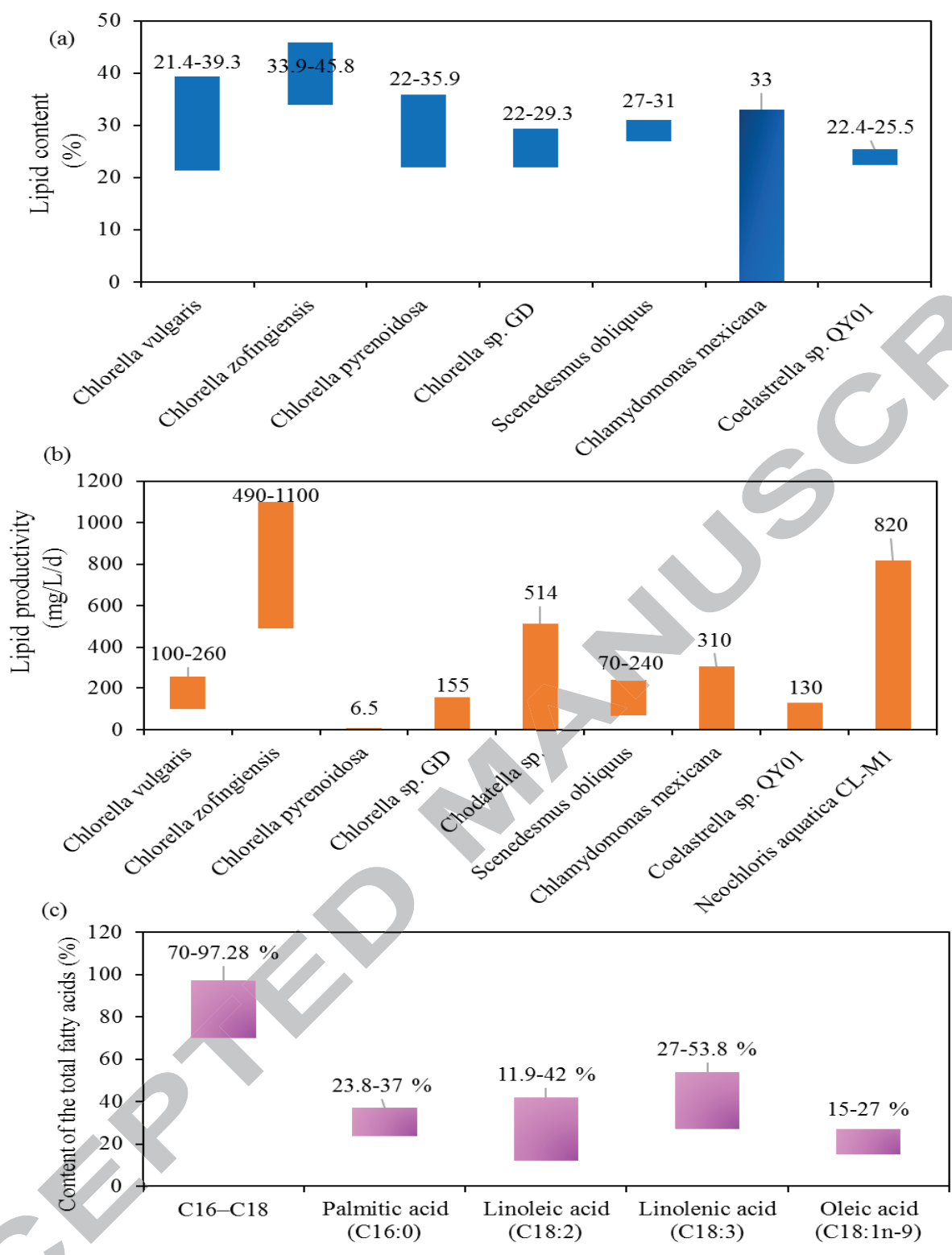

(d)

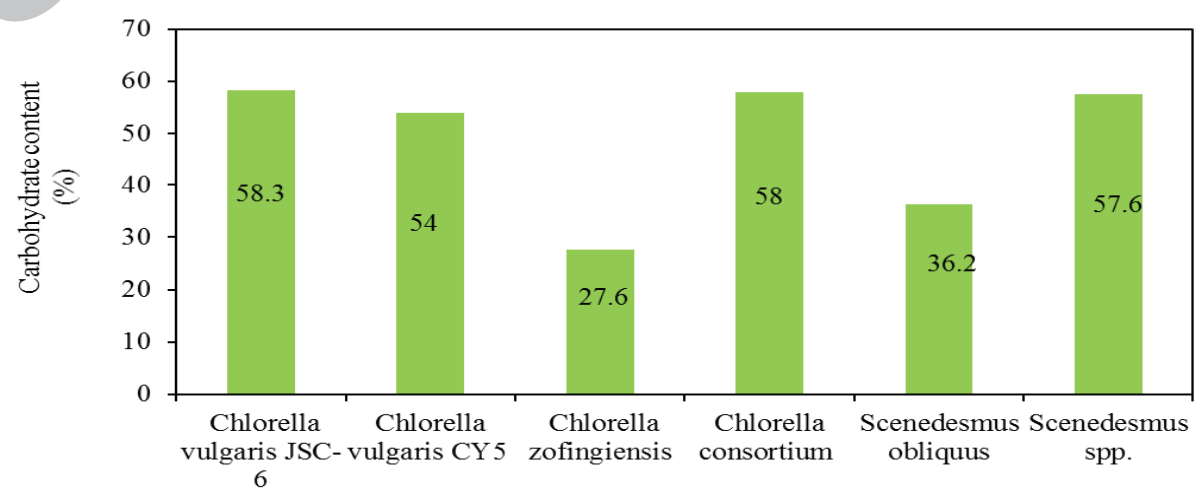

Fig. 3 Chemical composition of different microalgae species harvested from SW: (a) lipid contents; (b) lipid productivities; (c) Total fatty acid composition; (d) Carbohydrate contents 


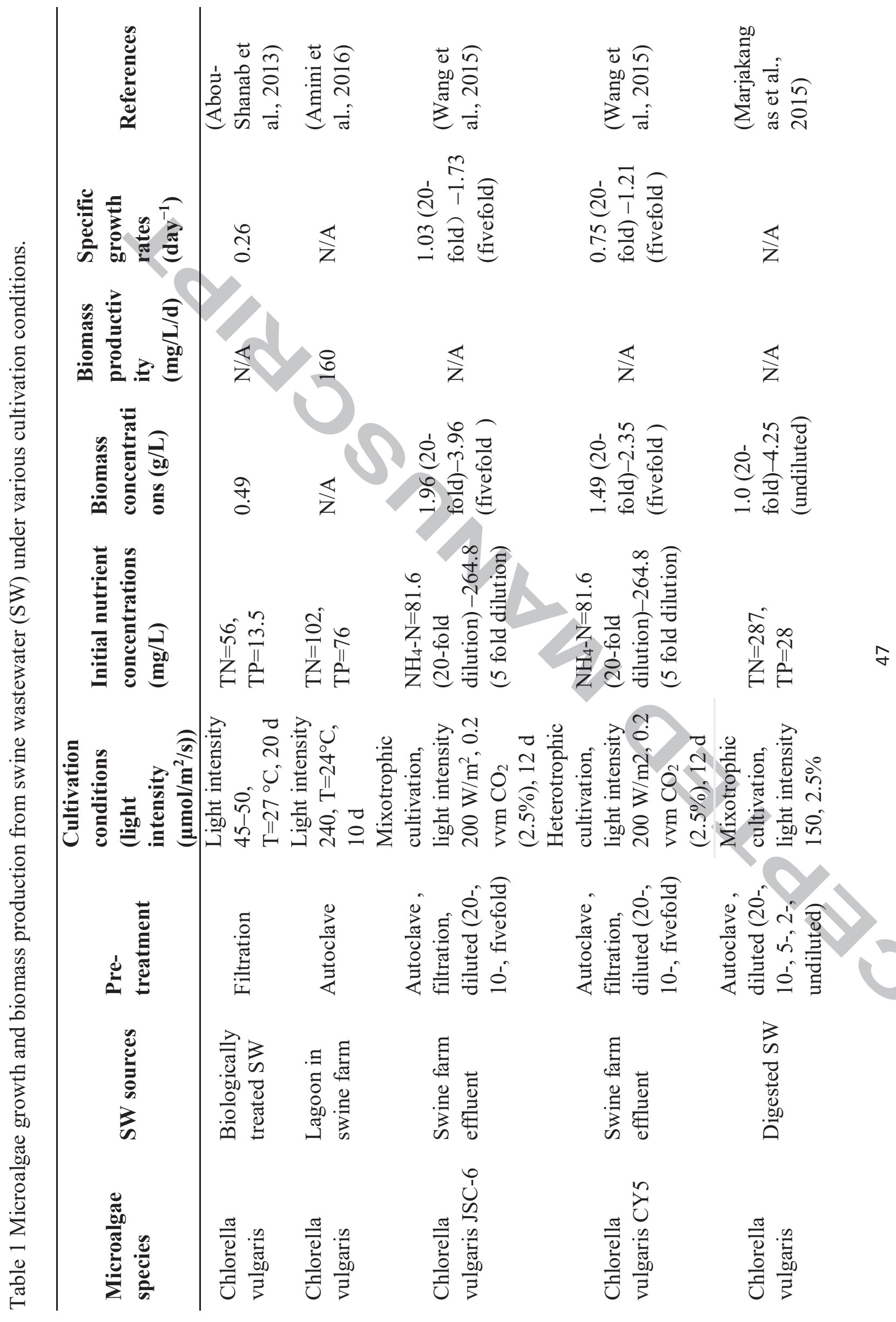



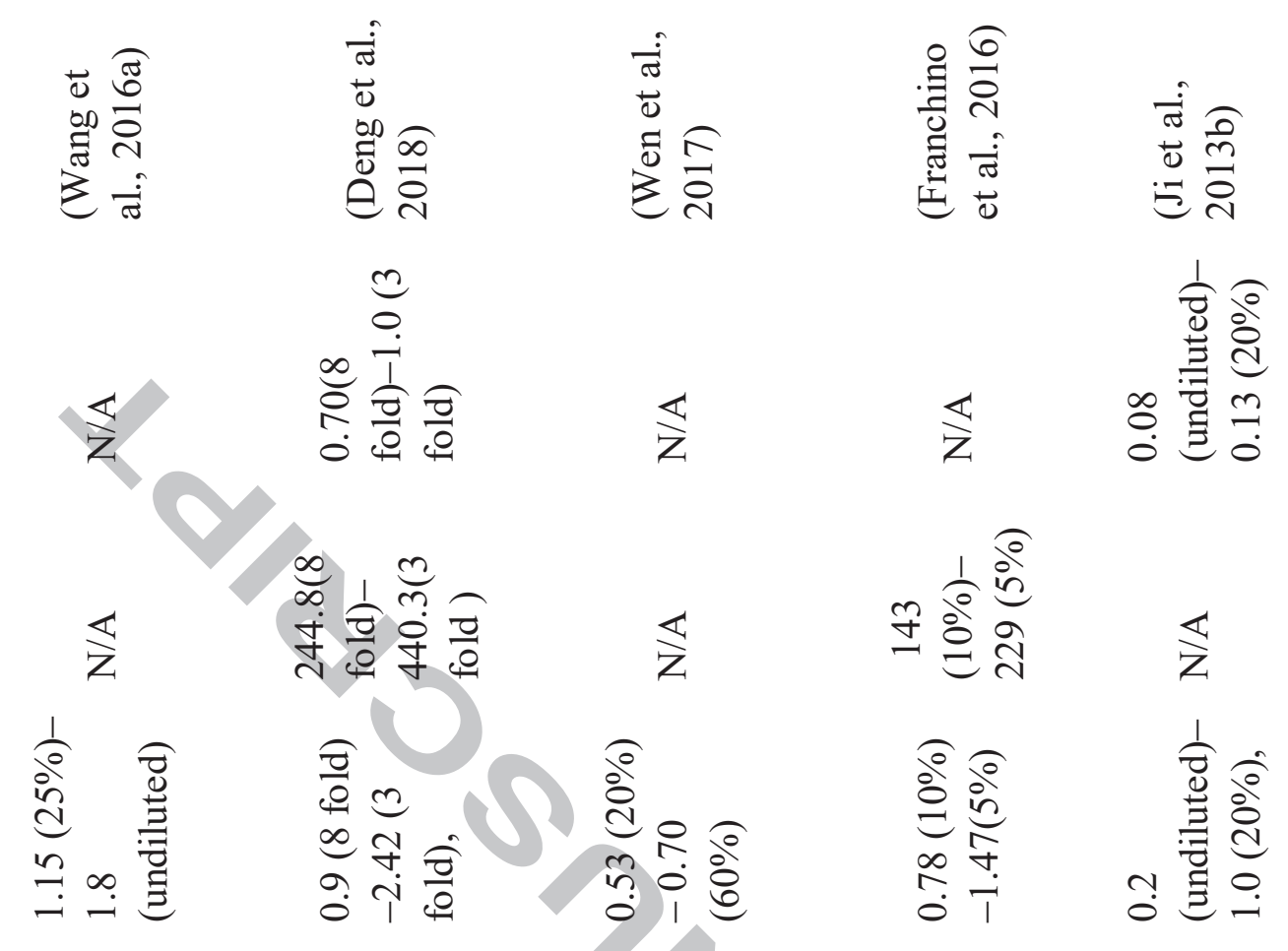

离志
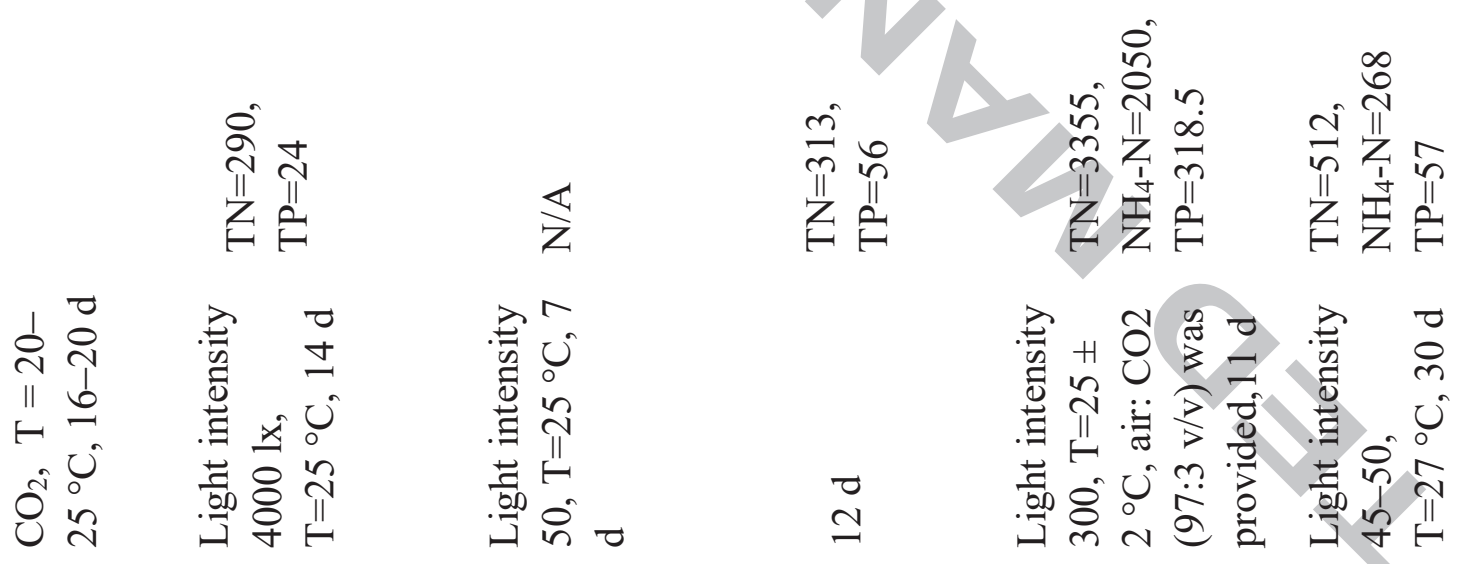

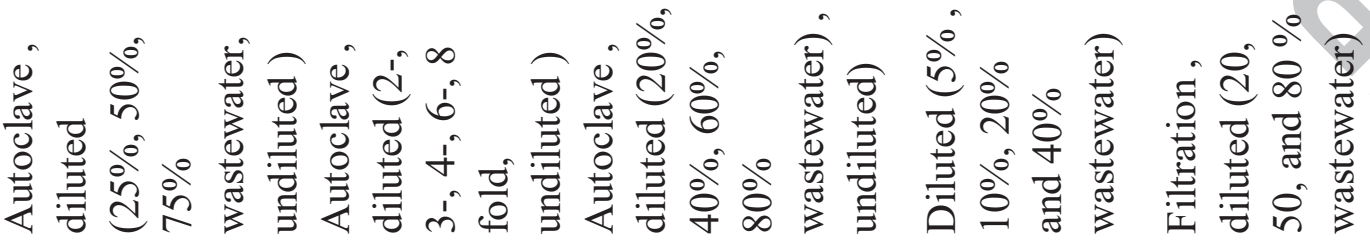

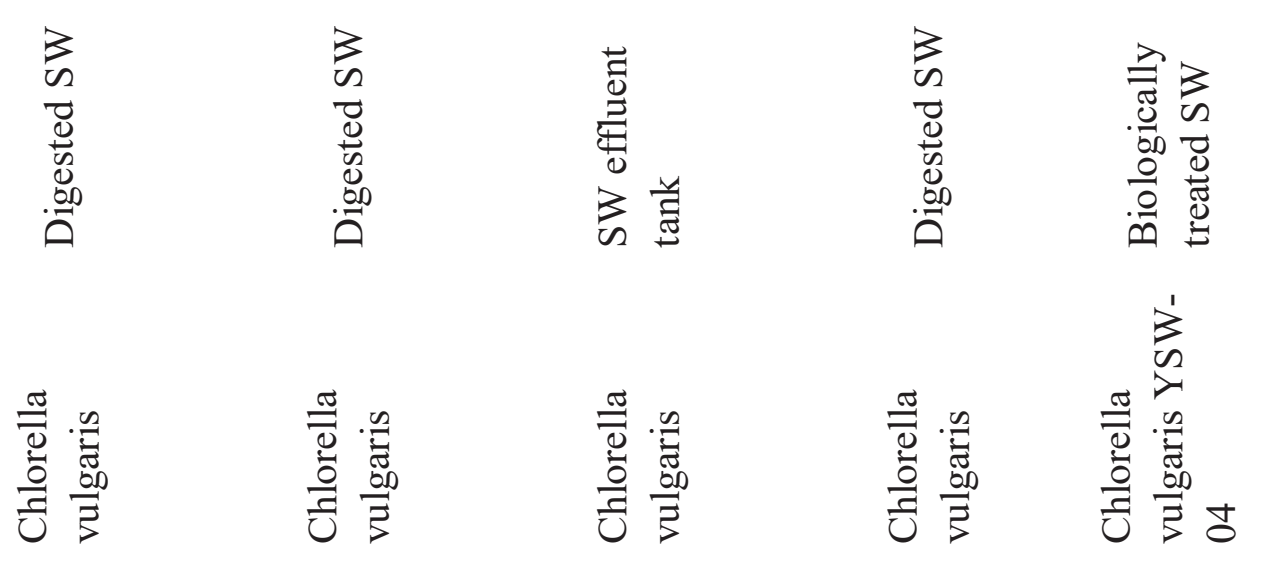




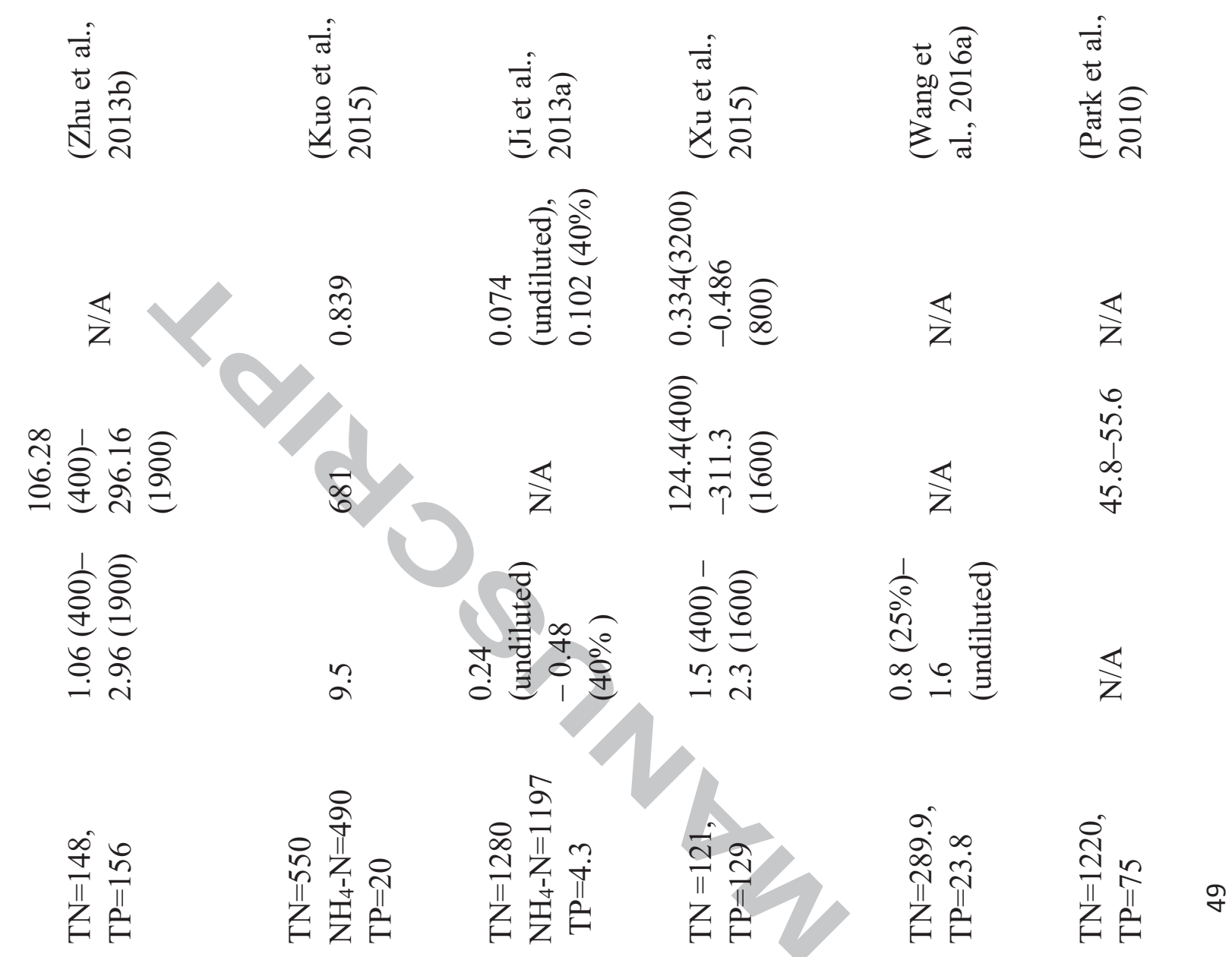

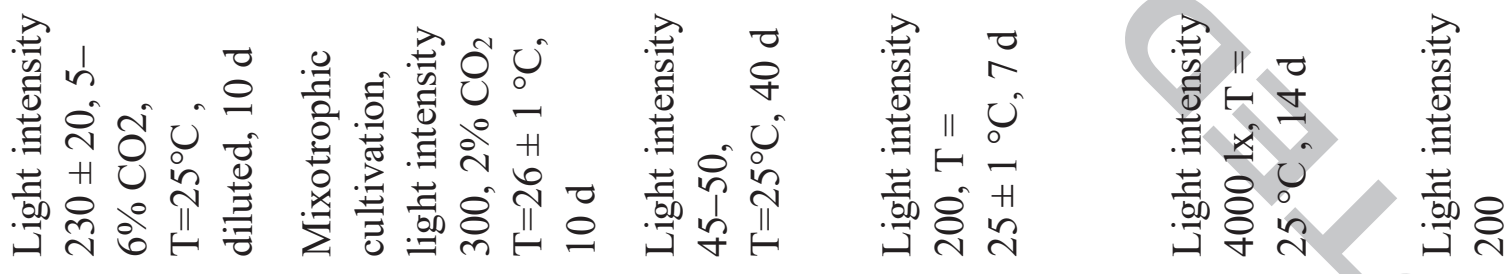

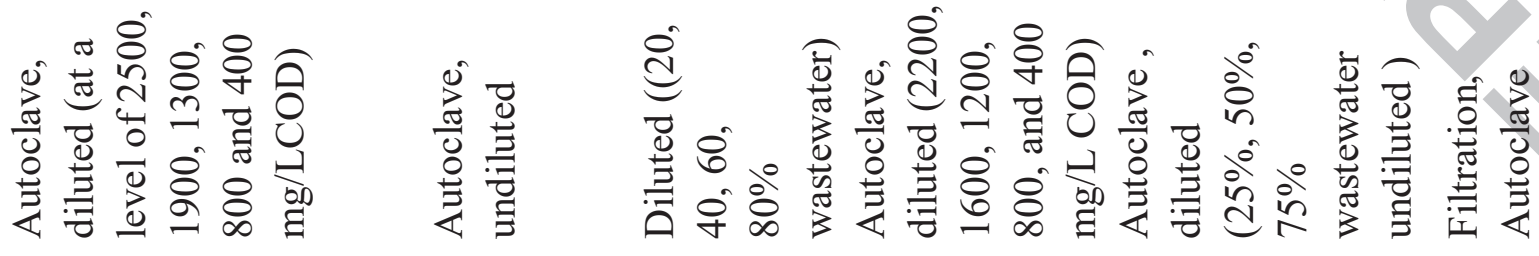
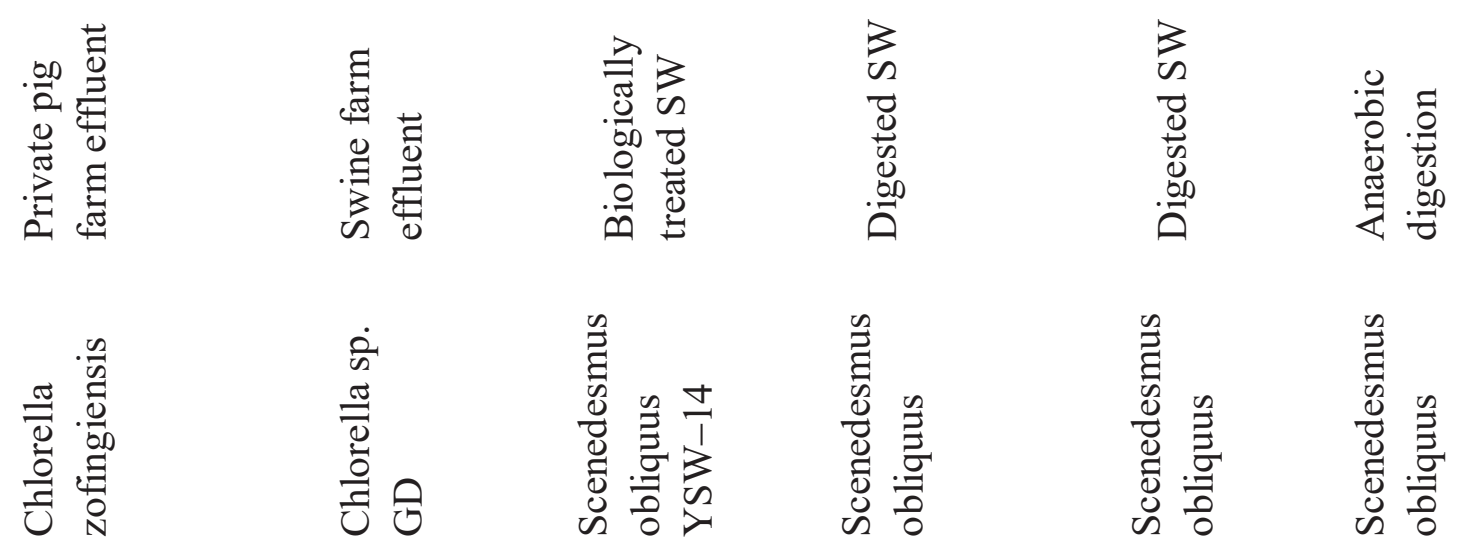


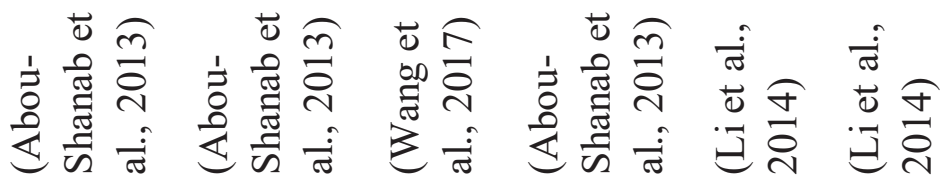

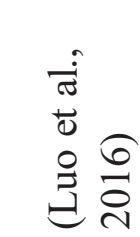

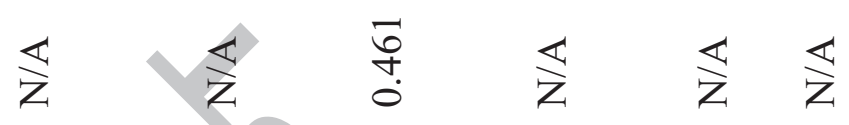

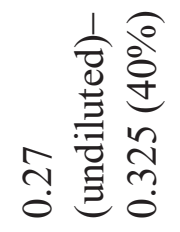

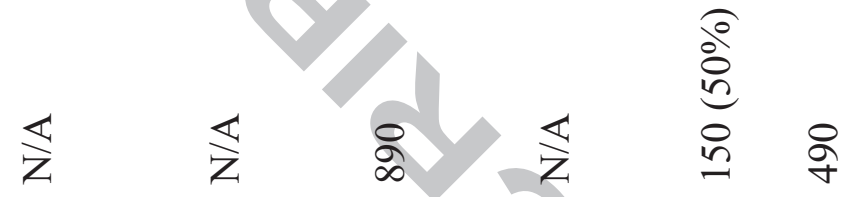

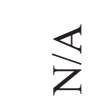

莺

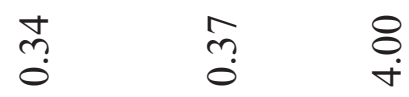

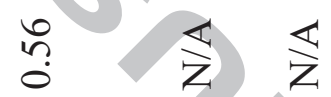

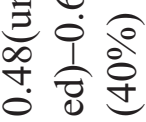

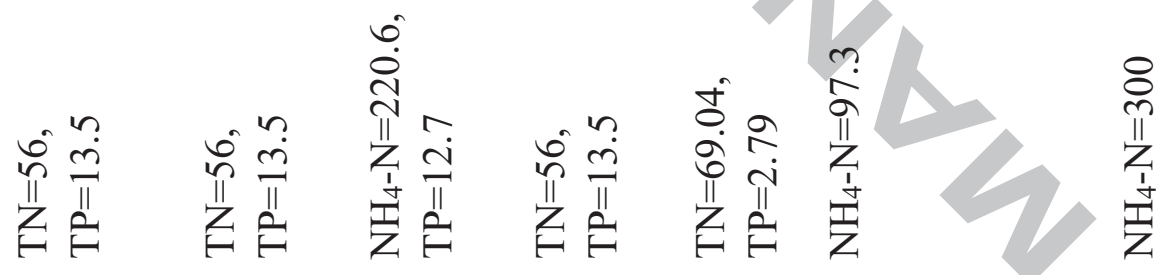

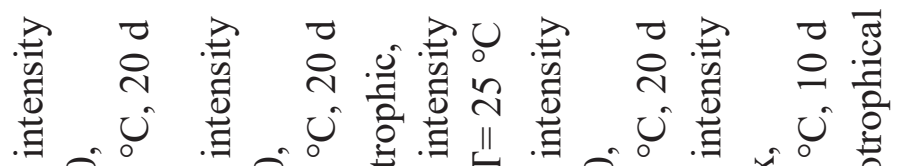

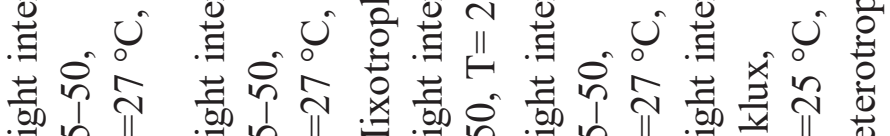

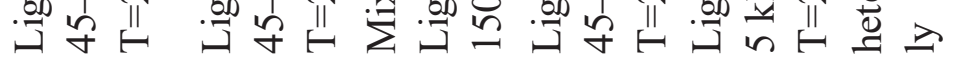

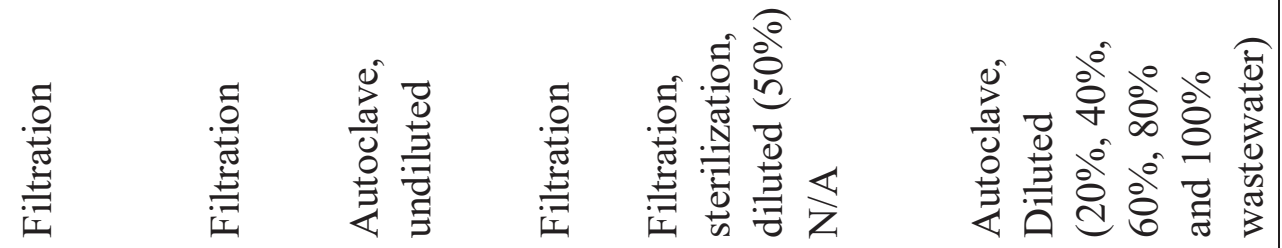

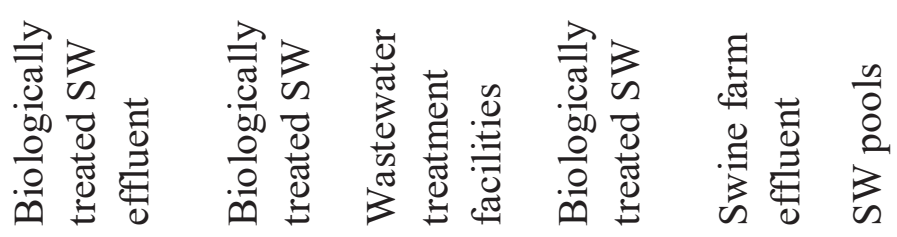

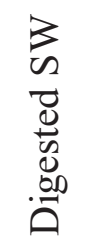

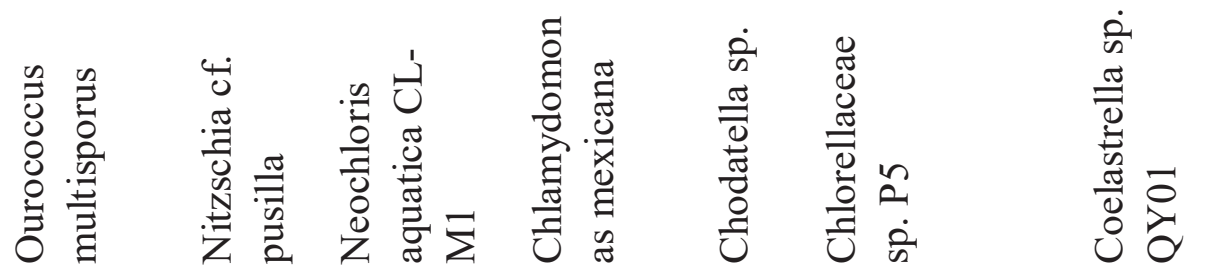

